\title{
Calibration Uncertainties of Tropical Pacific Climate Reconstructions over the Last Millennium
}

\author{
KYUNG-SOOK YUn AND AXEL TIMMERMANN \\ Center for Climate Physics, Institute for Basic Science, and Pusan National University, Busan, South Korea
}

(Manuscript received 18 August 2018, in final form 19 March 2019)

\begin{abstract}
Several climate field reconstruction methods assume stationarity between the leading patterns of variability identified during the instrumental calibration period and the reconstruction period. We examine how and to what extent this restrictive assumption may generate uncertainties in reconstructing past tropical Pacific climate variability. Based on the Last Millennium (850-2005 CE) ensemble simulations conducted with the Community Earth System Model and by developing a series of pseudoproxy reconstructions for different calibration periods, we find that the overall reconstruction skill for global and more regional-scale climate indices depends significantly on the magnitude of externally forced global mean temperature variability during the chosen calibration period. This effect strongly reduces the fidelity of reconstructions of decadal to centennial-scale tropical climate variability, associated with the interdecadal Pacific oscillation (IPO) and centennial-scale temperature shifts between the Medieval Climate Anomaly (MCA) and the Little Ice Age (LIA). In contrast, our pseudoproxy-based analysis demonstrates that reconstructions of interannual El Niño-Southern Oscillation (ENSO) variability are more robust and less affected by changes in calibration period.
\end{abstract}

\section{Introduction}

Tropical Pacific sea surface temperature anomalies (SSTA), associated with the El Niño-Southern Oscillation (ENSO) phenomenon and the interdecadal Pacific oscillation (IPO), generate widespread atmospheric circulation anomalies and can influence local climate and weather in regions far outside the Pacific. Reconstructions of this variability over the Last Millennium (LM) provide further insights into the range of natural variability and ENSO's potential response to external drivers, such as greenhouse gas, solar and volcanic forcings. A number of multiproxy network-based statistical methods have been applied to reconstruct past ENSO variability, using tropical Pacific climate proxies (Tierney et al. 2015; Wilson et al. 2010), as well as proxies from ENSO teleconnected regions (Coats et al. 2016; EmileGeay et al. 2013b; Li et al. 2013; McGregor et al. 2010). However, there still remains little coherence among the various reconstructions (e.g., Christiansen and Ljungqvist 2017; Hope et al. 2017; Wang et al. 2015). The uncertainties arise in part from the choice of different

\footnotetext{
Corresponding author: Axel Timmermann, timmermann@pusan. ac.kr
}

reconstruction methods and in part from differences in the underlying proxy data network. Better understanding of the uncertainties in reconstructions is therefore highly desirable to extend our knowledge of past and future ENSO variability.

Reconstructing multidecadal to centennial-scale climate variability in the tropical Pacific has been particularly difficult because of 1) the limited extent of instrumental data for calibration purposes, 2) insufficient availability of continuous annually resolving paleo-proxy data from ENSO-sensitive regions, and 3) prevailing tropical Pacific biases in long-term climate model simulations (Swingedouw et al. 2011). Current climate reconstruction efforts use a variety of proxy climate indicators such as tree rings, corals, speleothems, ice cores, and marine and lacustrine sediments in combination with advanced statistical methodologies (e.g., Christiansen et al. 2009; Emile-Geay et al. 2013b; Goosse et al. 2010; Hakim et al. 2016; Mann et al. 2008; Smerdon 2012; Tingley et al. 2012). To extract spatiotemporal information from a network of paleo-proxy datasets, covariance-based climate field reconstruction (CFR) techniques have been applied (e.g., Adams et al. 2003; Mann et al. 1998, 2009, hereinafter M09), which includes regularized expectation maximization (RegEM; 
Schneider 2001), optimal interpolation (Evans et al. 2002), canonical correlation analysis (CCA; Smerdon et al. 2010b), point-by-point regression (Anchukaitis et al. 2017), and Gaussian graphical models (Guillot et al. 2015). Moreover, paleo data assimilation applications have been proven beneficial to improve paleoclimate reconstructions (e.g., Hakim et al. 2016). The performance of CFR methods based on multivariate regression techniques (e.g., RegEM method) has been extensively studied in regard to influences of regularization schemes, detrending, hybrid separation of time scales, the correct representation of noise, geographic and seasonal biases of proxies, and misrepresentation of data (e.g., Bürger and Cubasch 2005; Christiansen et al. 2009; Mann et al. 2005a, 2007; McIntyre and McKitrick 2005; Rutherford et al. 2005; Smerdon and Kaplan 2007; Smerdon et al. 2010a; von Storch et al. 2004; Wahl et al. 2006; Zorita et al. 2007). Using LM simulations conducted with a coupled general circulation model (CGCM), von Storch et al. (2004) reported that some CFR methodologies (e.g., Mann et al. 1998) may reduce the amplitude of low-frequency variability in reconstructions of global mean surface temperature. The criticism raised by von Storch et al. (2004) initiated vigorous discussion on the fidelity of CFR methodologies (e.g., Mann et al. 2005a, 2007; Smerdon and Kaplan 2007; Wahl et al. 2006; Zorita et al. 2007). Mann et al. (2007) demonstrated using a pseudoproxy study that the RegEM-truncated total least squares [RegEM-TTLS, developed by Schneider (2001)] method has advantages over Ridge regression used previously (Mann et al. 2005a; Rutherford et al. 2005). To further improve the fidelity of multiproxybased temperature reconstruction methods, M09 implemented the RegEM-TTLS algorithm. Although the skill of reconstructing spatial features of past temperature variability is still very much limited, the temporal evolution of hemispherically and globally averaged temperatures is represented well by the current generation of CFR-based methods (Christiansen and Ljungqvist 2017; Evans et al. 2014; Smerdon et al. 2011, 2016; Wang et al. 2015).

Covariance-based reconstruction methods require observational inputs, which are usually obtained from the available instrumental datasets covering the past 80-150 yr. However, this period can be regarded as a noanalog situation with global mean surface temperatures increasing because of increasing greenhouse gas emissions (see Fig. A1 in the appendix). There are several studies demonstrating that changing the calibration period from the late nineteenth to the twentieth century may introduce considerable biases and uncertainties in reconstructions, owing to different representations of the patterns of low-frequency variability (Esper et al. 2005; Frank et al. 2010). These studies imply that calibrating temperature reconstructions using a no-analog situation may cause severe errors in reconstructions of regional-scale climate variability (e.g., ENSO and IPO) prior to the industrial revolution. Mathematically expressed, the covariance-based CFR approach assumes that the leading patterns of variability during the instrumental calibration period remain the leading patterns of past low-frequency variability (see section $2 b$ and appendix for details). The leading empirical orthogonal function (EOF) mode of instrumental temperature variability (i.e., the first leading pattern of HadCRUT3 observation during 1850-1995; Fig. 1b) essentially captures the global warming signal in terms of pattern and time evolution. Instrumental data, which include the global warming trend, provide only limited information about past externally forced temperature variability. Moreover, ENSO's potential response to external drivers has not been well understood (e.g., Hope et al. 2017; Wilson et al. 2010). Despite several efforts to test this nonstationarity issue (Christiansen 2011; Christiansen et al. 2009; Esper et al. 2005; Pyrina et al. 2017; Rutherford et al. 2003), it still remains unclear whether the choice of a twentieth-century calibration period will affect regional-scale CFRs of internally generated and externally forced LM temperature variability in key areas such as the tropical Pacific.

To test how and to what extent the assumption of stationary twentieth-century covariances may influence reconstructions of past ENSO and IPO variability, we performed pseudoproxy reconstructions using surface temperature variability simulated by the 10 -member Community Earth System Model (CESM)-LM ensemble covering the period from 850 to 2005 Common Era (CE). For this approach, we applied the RegEM-TTLS method of M09. We also used different calibration periods representing 146-yr sliding segments during the LM simulation, including the twentieth-century section. These segments are characterized by different climatic background states and by different levels of externally forced variability. The pseudoproxy method is a useful tool for investigating the characteristics of CFR methods because the model simulation can provide a spatiotemporally complete field of predictor and predictand variables (e.g., Smerdon 2012). To this end, LM simulations from fully coupled climate models (Fernández-Donado et al. 2013; Otto-Bliesner et al. 2016; PAGES Hydro2K Consortium 2017) have helped in understanding limitations and uncertainties of climate reconstruction methods (Christiansen and Ljungqvist 2017; Smerdon and Pollack 2016). 
(a) GMT variability (1850-1995 cali.) and 21 differnet calibration periods
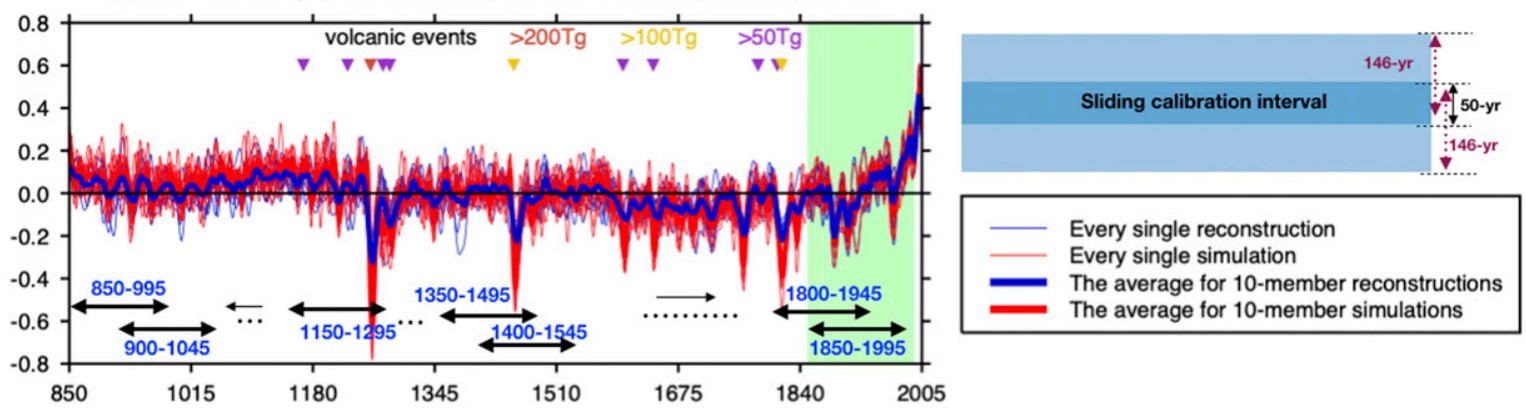

(b) Pseudoproxy network and Instrumental EOF1 pattern (21.0\%)

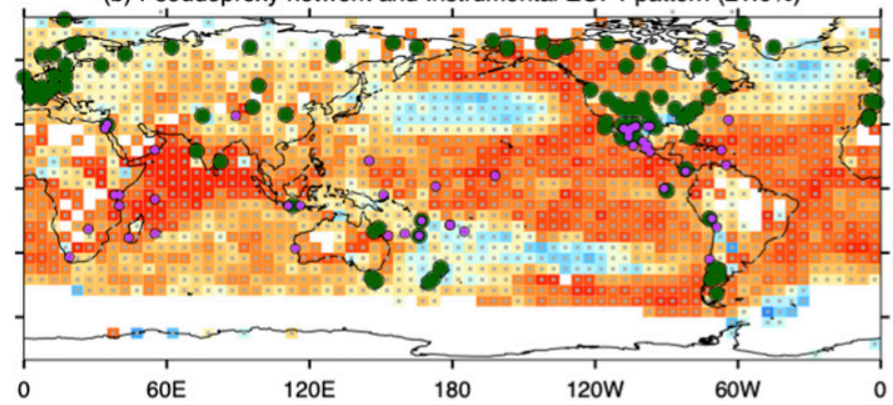

\footnotetext{
Pseudoproxy network from Mann et al. (2009; \#104, M09)

- Pseudoproxy network from Emile-Geay et al.(2013; \#48, EG)

- Reconstruction grids (\#1730)

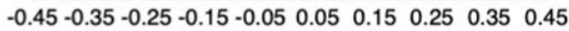
Instrumental EOF1 pattern during $1850-1995\left[^{\circ} \mathrm{C}\right]$
}

FIG. 1. (a) The reconstructed 10-yr low-pass-filtered global mean surface temperature (GMT) time series in a reference "M09" experiment (blue; see Table 1) and the GMT time series simulated by the CESM LM ensemble (red) are displayed for individual 10 members (thin) and the mean of 10 member (thick). The reference reconstruction was based on a calibration period of 1850-1995 and signal-tonoise-ratio (SNR) of 0.4 (i.e., CALI1850-1995). The major volcanic eruptions used in the CESM-LM simulation (Gao et al. 2008) are displayed with triangle symbols. Based on 10-member ensemble of CESM-LM simulation, the calibration in each reconstruction was performed using predictor (104-grid pseudoproxy data sampled from CESM-LM) and predictand (1730-grid CESM-LM simulation data) for a 146-yr window, sliding from the period 850-995 to 1850-1995 with 50-yr lag time. (b) The first leading pattern of temperature variability from instrumental HadCRUT3 dataset during 1850-1995 CE (shading). The reconstruction target field (gray box) and pseudoproxy network locations are also indicated in green circle (network from M09) and in purple circle (network from Emile-Geay et al. 2013b). The final pseudoproxy reconstructions, with 210 different combinations of 10 -member ensemble and 21 calibration periods, were generated using 1730 grid points covering $1156 \mathrm{yr}$ (850-2005 CE).

\section{Data and methods}

\section{a. Surface temperature data from CESM-LM model simulation}

To test the stability of the covariance-based CFR method with respect to different calibration periods, we use pseudoproxies that are obtained from annual mean surface temperature fields simulated by a 10 -member ensemble of externally forced LM simulations from 850 to $2005 \mathrm{CE}$. The LM simulations were conducted with the CESM (Otto-Bliesner et al. 2016). The CESM-LM simulations include solar, volcanic, land use, greenhouse gas, and orbital forcings. Simulated global mean surface temperatures agree well with the M09 reconstruction (Otto-Bliesner et al. 2016). The CESM-LM experiment also reproduces the response to large volcanic eruptions (such as 1258, 1452, and 1815 CE) (Gao et al. 2008) (Fig. 1a). The difference between the individual ensemble members is in the application of small random roundoff perturbations in the air temperature field from a long control simulation at the $850 \mathrm{CE}$ start time of each ensemble member. We apply the pseudoreconstruction approach to each of the 10-member ensemble simulations separately. The CESM model field is interpolated onto the same resolution of $5^{\circ} \times 5^{\circ}$ resolution grid $(72 \times 36)$, as for the calibration and reconstruction field used by M09. Anomalies in the CESM-LM simulation are calculated by removing the mean of the reference period 1961-90 CE, as in the instrumental HadCRUT3 dataset (Brohan et al. 2006). The low-frequency (LF) and high-frequency (HF) components were also calculated by applying low-pass and high-pass filters with a cutoff frequency of $f=0.1$ cycles per year, using a 10-point Butterworth filter.

To estimate the externally forced response in each ensemble simulation, global mean surface temperature (GMT) anomalies, calculated by area-weighted averaging the 10-yr low-pass filtered surface temperature anomalies over the globe, were used as an indicator of the externally forced component (Ting et al. 2009; 
TABLE 1. A control experiment (i.e., "M09") and four sensitivity experiments of pseudoproxy reconstructions in terms of proxy network, hybrid frequency split, and signal-to-noise ratio at high frequency (HF) and low frequency (LF). Each experiment is composed of 210 reconstructions for different combinations of 10 -member ensemble and 21 different calibration periods. The correlations between CESM-LM simulation and reconstructions (i.e., CC_skill) with the calibration period of 1850-1995 (CALI1850-1995) in constructing Niño-3 time series are represented by the mean \pm interensemble standard deviation within the 10 -member ensemble.

\begin{tabular}{|c|c|c|c|c|c|}
\hline \multicolumn{2}{|c|}{ Experiment } & \multirow{2}{*}{$\frac{\text { Proxy network }}{104 \text { from Mann et al. (2007) }}$} & \multirow{2}{*}{$\begin{array}{l}\text { Hybrid frequency } \\
\text { split }\left(f_{s}\right) \\
0.05 \mathrm{yr}^{-1}\end{array}$} & \multirow{2}{*}{$\begin{array}{c}\begin{array}{c}\text { Signal-to-noise } \\
\text { ratio (SNR) }\end{array} \\
0.4 \text { at both } \mathrm{LF} \text { and } \mathrm{HF}\end{array}$} & \multirow{2}{*}{$\frac{\text { CC_skill in CALI1850-1995 }}{0.43 \pm 0.1 \text { at } \mathrm{LF} / 0.66 \pm 0.03 \text { at } \mathrm{HF}}$} \\
\hline Control & M09 & & & & \\
\hline \multirow[t]{4}{*}{ Sensitivity } & EG & $\begin{array}{l}48 \text { from Emile-Geary et al. } \\
\text { (2013b) }\end{array}$ & $0.05 \mathrm{yr}^{-1}$ & 0.4 at both LF and HF & $\begin{array}{l}0.45 \pm 0.15 \text { at } \mathrm{LF} / 0.75 \pm 0.02 \\
\text { at } \mathrm{HF}\end{array}$ \\
\hline & FRE0.1 & 104 from Mann et al. (2007) & $0.1 \mathrm{yr}^{-1}$ & 0.4 at both $\mathrm{LF}$ and $\mathrm{HF}$ & $\begin{array}{l}0.45 \pm 0.07 \text { at } \mathrm{LF} / 0.65 \pm 0.03 \\
\quad \text { at } \mathrm{HF}\end{array}$ \\
\hline & DIFFnoise & 104 from Mann et al. (2007) & $0.05 \mathrm{yr}^{-1}$ & $\begin{array}{l}0.4 \text { at } \mathrm{HF} \text { and } 0.4 \times \\
\sqrt{1 / f_{s}} \text { at LF }\end{array}$ & $\begin{array}{l}0.45 \pm 0.07 \text { at } \mathrm{LF} / 0.68 \pm 0.03 \\
\text { at } \mathrm{HF}\end{array}$ \\
\hline & INF & 104 from Mann et al. (2007) & $0.05 \mathrm{yr}^{-1}$ & $\begin{array}{l}\text { INF at both LF and } \\
\text { HF (no noise) }\end{array}$ & $\begin{array}{l}0.64 \pm 0.06 \text { at } \mathrm{LF} / 0.82 \pm 0.01 \\
\text { at } \mathrm{HF}\end{array}$ \\
\hline
\end{tabular}

Trenberth and Shea 2006). Following M09, tropical Pacific climate variability is represented as the Niño-3 SST anomalies averaged over the grid boxes $\left(2.5^{\circ} \mathrm{S}-2.5^{\circ} \mathrm{N}\right.$, $147.5^{\circ}-92.5^{\circ} \mathrm{W}$ ) and the HF (LF) Niño-3-correlated spatial pattern will be referred to as the ENSO teleconnection (IPO) pattern. In M09, the first two leading patterns of observed temperature variability represent the externally forced global warming pattern and the ENSOteleconnection pattern, respectively. In addition, following M09, three other regional indices are calculated by the area-averaged temperature mean over the tropical (TP; $27.5^{\circ} \mathrm{S}-27.5^{\circ} \mathrm{N}, 177.5^{\circ} \mathrm{E}-177.5^{\circ} \mathrm{W}$ ) and extratropical (EXP; $\left.27.5^{\circ}-67.5^{\circ} \mathrm{N}, 177.5^{\circ} \mathrm{E}-177.5^{\circ} \mathrm{W}\right)$ bands, and the Atlantic main development region for hurricanes (MDR; 7.5 $\left.17.5^{\circ} \mathrm{N}, 175^{\circ}-62.5^{\circ} \mathrm{W}\right)$.

\section{b. CFR procedure using RegEM algorithm}

RegEM algorithms have been successfully applied to reconstruct large-scale climate variability at interannual and decadal time scales (e.g., Emile-Geay et al. 2013b; Mann et al. 2008). Here, we reconstructed the surface temperature fields using the RegEM-TTLS CFR procedure of M09. Unlike the original RegEM-TTLS (Schneider 2001), the M09 applied the hybrid frequency domain that separates the reconstruction for lowfrequency and high-frequency signals. We follow the CFR procedure of M09, including a forward "stepwise" reconstruction approach, a version of RegEM TTLS, an optimal choice of truncation parameter, and hybrid frequency-domain RegEM CFR procedure where highfrequency $(f>0.05$ cycles per year) and low-frequency $(f<0.05$ cycles per year) components of the reconstruction are calibrated separately. Compared to previous studies focusing on a single index (Emile-Geay et al. 2013b; McGregor et al. 2015), M09 targeted a global climate field with globally distributed proxies (see Fig. 1b).
For better comparison, we chose the same proxy network as in M09, but applied the regional network mask to the pseudoproxies. Further details are represented in the supplemental material of M09. The pseudoproxy experiments that adopt the M09 CFR procedure will be referred to as the "M09" experiment (see Table 1).

Prior to the reconstruction we reduced the spatiotemporal number of degrees of freedom of the pseudoproxy dataset by truncating the EOF analysis and retaining only $M$ principal components (PCs). The number $M$ was estimated from the linear trend of the log-eigenvalue spectrum of the noise, leaving $\sim 5$ dominant modes. The retained EOF modes explain about $50 \%$ variance of the total variability. Although the explained variance is relatively small, Rutherford et al. (2010) demonstrated that larger truncation parameters degrade the RegEM-TTLS performance. The regression coefficients in RegEMTTLS were computed in a truncated space of PCs and regularization is accomplished through a choice of the truncation parameter $K$ (Mann et al. 2007). While the truncation parameter $K$ for high-frequency component is again calculated as a linear fit to the log-eigenvalue spectrum (i.e., almost same as $M$ ), the $K$ for low-frequency component is determined by estimating the eigenvalue rank taking $33 \%$ of the cumulative variance. For the pseudoproxy reconstructions, $K$ for the low-frequency component attains values of $\sim 2$. Therefore, the spatial patterns in the RegEM CFR procedure are reconstructed by using the spatiotemporal information of the first $M$ leading LF and HF EOF modes of the annual mean field from the overlap segment between instrumental and proxy data.

As noted by M09, the first leading mode during the modern instrumental interval (i.e., 1850-1995 CE) represents mostly the low-frequency variability associated with the surface temperature response to increasing greenhouse gas concentrations (also see Fig. A1). The 
second and higher modes represent internal variability associated with ENSO, the IPO, and the Atlantic multidecadal oscillation temperature pattern. Whereas the leading patterns in the instrumental data are captured by the 10-member ensemble mean (ENS) of the CESMLM simulation, the leading patterns in each ensemble simulation are somewhat different from those in the instrumental observation: the first mode represents the internal mode associated with ENSO and IPO, which reflects a stronger internal variability in the model than in the observations (see Figs. A1 and A2). The simulated leading patterns are a function of the calibration period, which challenges the stationarity assumption for the leading patterns of low-frequency variability.

\section{c. Pseudoproxy reconstruction with different calibration periods}

For the calibration period under consideration, we subsampled each simulated temperature field at 104 pseudoproxy locations (predictor) from the CESM LM ensemble (Fig. 1b). The predictand comprises the target temperature field during the calibration period (1730 grid points). The 104 pseudoproxy locations correspond to the proxy locations used in Mann et al. (2007; M09). The final pseudoproxy reconstruction in our study covers 1730 spatial points and 1156-yr time points (8502005 CE) (Fig. 1). Similar to M09, we choose a 146-yr window for the calibration period. To study the stationarity of the reconstructions, we choose different calibration periods in our pseudoproxy modeling approach. This was done for each ensemble member by sliding the 146-yr calibration window from the period 850-995 CE to 1850-1995 CE and using 50-yr intervals (i.e., 21 different calibration periods; Fig. 1a). The different calibration periods (CALI) capture a broader range of externally forced and internally generated climate variability than just for the twentieth century. In total, we generated 210 pseudoproxy reconstructions with 21 calibration periods for each of the 10 CESM-LM ensemble members.

In general, pseudoproxies are generated by degrading local surrogate normalized temperatures $S(x, t)$ by adding noise. In this study, we construct pseudoproxies $P(x, t)$ at each grid point $x$ and time $t$ using a Gaussian white-noise model [i.e., $P(x, t)=S(x, t)+N(x, t) / \mathrm{SNR}$ ], where SNR represents the signal-to-noise ratio, which effectively controls the amplitude of the noise $N(x, t)$. A SNR level of 0.4 is used for our study that corresponds to a correlation of 0.37 between model simulated temperatures and pseudoproxies. Such a SNR level is similar to that of real-world proxy networks (e.g., Mann et al. 2007). All validation statistics in this study were calculated for the entire time interval from
850 to $2005 \mathrm{CE}$. Using the calibration period from 1850 to 1995 CE (i.e., CALI1850-1995), we first reconstruct global mean LM surface temperatures for every single ensemble member and using the pseudoproxy network (Fig. 1a). This result documents a high performance of the RegEM CFR methodology in reconstructing GMT variability, albeit with a known loss in variance (e.g., Christiansen and Ljungqvist 2017). It should be also noted that the high skill of GMT reconstruction does not necessarily translate into reliable spatial skills (Smerdon et al. 2016).

\section{d. Sensitivity experiments: SNR, proxy network, and hybrid frequency split}

We performed additional experiments to test the sensitivity of the reconstruction with respect to SNR, proxy network, and hybrid frequency split (i.e., $f_{s}$ ). To examine the impact of SNR, pseudoproxy experiments were first performed for 10 different values of SNR, covering the range from 0.1 to 1.0 with a 0.1 interval. In addition, we carried out a perfect pseudoproxy experiment (no added noise, SNR $=\infty$ ), called the "INF" experiment (see Table 1). It should be also noted that the SNR in the HF band is commonly the same as in the LF band, even though the calibration process is separately done for $\mathrm{HF}$ and $\mathrm{LF}$. If the $\mathrm{LF} / \mathrm{HF}$ variance ratio is $f_{s}$, we can use the central limit theorem to express the estimated noise standard deviation (STD) at LF (i.e., $\left.\sigma_{\mathrm{LF}}\right)$ and SNR by

$$
\sigma_{\mathrm{LF}}^{2}=f_{s} \sigma_{\mathrm{HF}}^{2}, \mathrm{SNR}_{\mathrm{LF}}=\sqrt{1 / f_{s}} \mathrm{SNR}_{\mathrm{HF}} .
$$

For example, the SNR at LF can be different from SNR of 0.4 at $\mathrm{HF}$; that is, $0.4 \times \sqrt{1 / f_{s}}$. The different noise level indicates a larger noise variability at $\mathrm{HF}$ rather than LF, which is called "DIFFnoise" experiment (see Table 1).

Using 48 ENSO-teleconnected proxies equatorward of $35^{\circ}$ (see Fig. 1b; purple circles), Emile-Geay et al. (2013b) reconstructed past ENSO variabilities following the M09 methodology. They used a hybrid frequency domain with a 10 -yr low-pass cutoff $\left(f_{s}=0.1\right.$ cycles per year $)$. To determine the influence of different pseudoproxy networks and frequency splits applied in Emile-Geay et al. (2013b), we run additional pseudoproxy reconstruction experiments ("EG" and "FRE0.1") (see Table 1).

\section{Results}

\section{a. Basic performance of CFR reconstructions}

We first examine the performance of pseudoproxy reconstructions for GMT variability for the period 850-2005 
(a) GMT, 10-year lowpass, SNR= 0.4

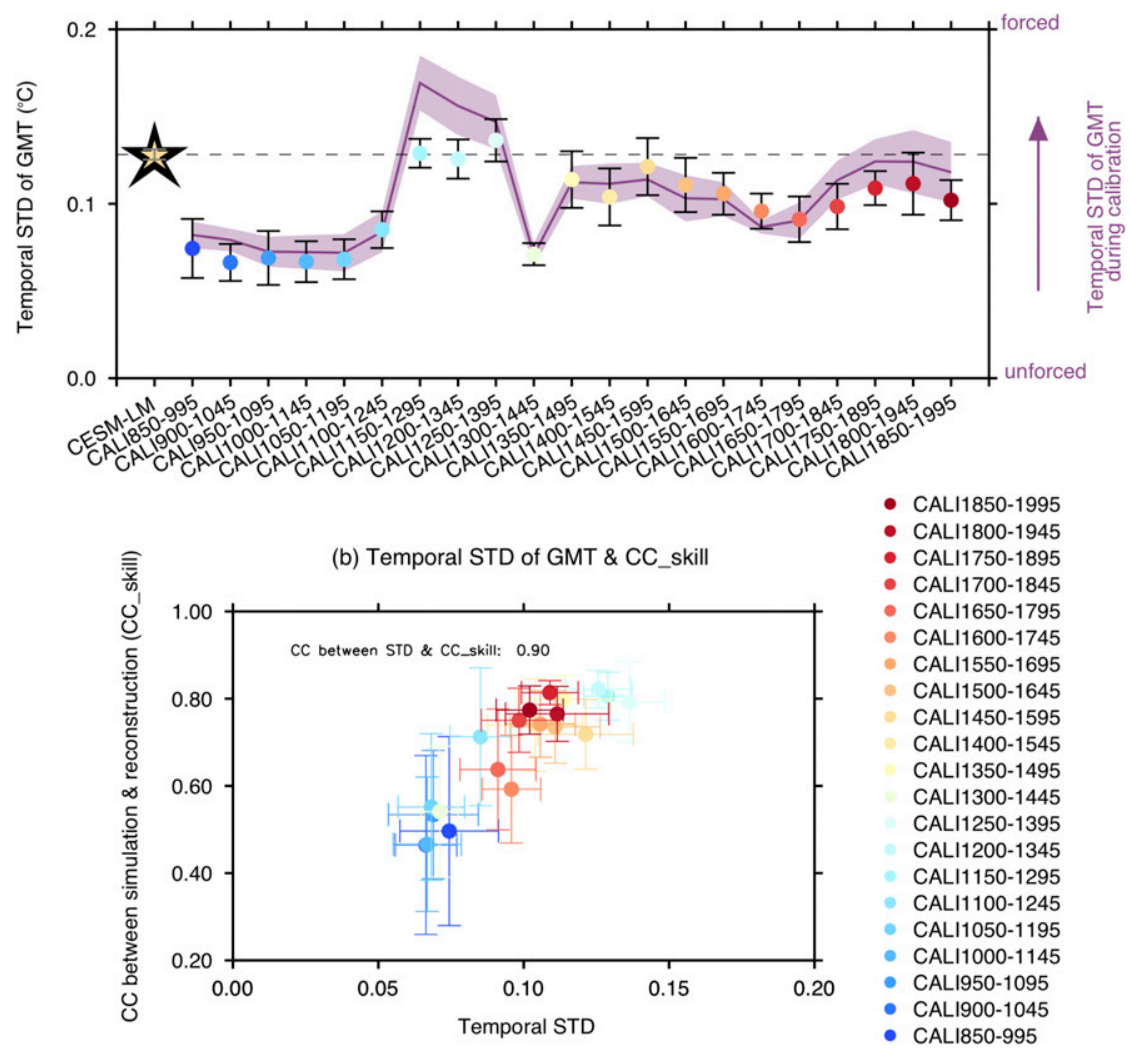

FIG. 2. (a) Temporal standard deviations (STDs) of (10-yr low passed) GMT time series for the CESM-LM simulation (star symbol) and pseudoproxy reconstructions (circle) from "M09" experiment (total 210 reconstructions with 10-member ensemble and 21 difference calibration periods): the mean of 10 ensemble members (filled symbol) and interensemble STDs within 10 members (error bar). The interensemble STD represents the spread of reconstructions (or simulations) within 10-member ensemble, while the temporal STD indicates the amplitude of variability during the target period 850-2005. The purple line and shading indicate the mean and interensemble STD of GMT temperature variability from the CESM-LM simulation during individual calibration subperiods, with varying amplitudes of externally forced variability during each calibration period. (b) Reconstructed GMT variabilities vs correlation coefficients (CCs) between simulation and reconstruction (i.e., CC_skill) for GMT time series in 21 individual reconstructions: the mean of 10 ensemble members (filled circle) and interensemble STD (error bar). This indicates that the externally forced GMT variabilities are related to the final GMT reconstruction skill.

CE. Fig. 2a shows the temporal STD for reconstructions that are based on different calibration periods in comparison with the original STD from CESM-LM simulation (star). The filled circles and error bars indicate the mean and interensemble STD for the 10 members. In agreement with previous studies (e.g., Christiansen et al. 2009; Pyrina et al. 2017; von Storch et al. 2004), we show an underestimation of the reconstructed GMT variance relative to the original simulation. There is also a large spread of the amplitude of reconstructed GMT variabilities for different calibration periods. Reconstructions with strong external forcing (e.g., due to volcanic eruptions; CALI1150-1295) and hence larger global mean temperature variability during the calibration period (purple line and shading) exhibit larger reconstructed GMT variability for the target interval (850-2005 CE), in accordance with a previous study (Wang et al. 2014).

We also find a strong relationship between the amplitude of reconstructed GMT variabilities and the correlation skill between original simulation and reconstruction (Fig. 2b). The correlation coefficient skill will hereafter be referred to as CC_skill (Fig. 2b). Reconstructions exhibiting high values of GMT STD, such as the ones calibrated relative to a period with strong volcanic eruptions or modern global warming, have a better performance for GMT, whereas reconstructions 
TABLE 2. Relationship between reconstructed 10-yr low-passed global mean surface temperature (GMT) variability (i.e., standard deviation; STD), CC_skill, and GMT covariance for regional low-frequency (LF; 10-yr low passed) indices obtained from "M09" experiment, where the correlation is calculated using 21 individual reconstructions averaged over 10-member ensemble of these variables. The GMT covariance (unit: \%) indicates the covariance of regional time series explained by GMT variability, which is measured by the square of correlation between GMT and regional indices time series during the target period 850-2005. The TP, EXT, and MDR regional indices are calculated by the area-averaged temperature mean over the tropical (TP; $\left.27.5^{\circ} \mathrm{S}-27.5^{\circ} \mathrm{N}, 177.5^{\circ} \mathrm{E}-177.5^{\circ} \mathrm{W}\right)$, extratropical $\left(\mathrm{EXP} ; 27.5^{\circ}-67.5^{\circ} \mathrm{N}, 177.5^{\circ} \mathrm{E}-177.5^{\circ} \mathrm{W}\right)$, and Atlantic main development SST region for hurricanes $\left(\mathrm{MDR} ; 7.5^{\circ}-17.5^{\circ} \mathrm{N}, 175^{\circ}-62.5^{\circ} \mathrm{W}\right)$.

\begin{tabular}{|c|c|c|c|c|}
\hline & Niño-3 & $\mathrm{TP}$ & EXT & MDR \\
\hline $\begin{array}{l}\text { CC_skill (mean } \pm \text { STD within } 21 \\
\text { reconstructions) }\end{array}$ & $0.43 \pm 0.04$ & $0.60 \pm 0.10$ & $0.57 \pm 0.13$ & $0.48 \pm 0.07$ \\
\hline $\begin{array}{l}\text { GMT covariance (mean } \pm \text { STD within } \\
21 \text { reconstructions) }\end{array}$ & $22 \% \pm 15 \%$ & $90 \% \pm 3 \%$ & $55 \% \pm 21 \%$ & $59 \% \pm 8 \%$ \\
\hline Correlation (GMT variability vs CC_skill) & 0.33 & 0.89 & 0.79 & 0.75 \\
\hline $\begin{array}{l}\text { Correlation (GMT variability vs GMT } \\
\text { covariance) }\end{array}$ & -0.83 & 0.67 & 0.94 & 0.28 \\
\hline $\begin{array}{l}\text { Correlation (GMT covariance vs } \mathrm{CC}_{-} \\
\text {skill) }\end{array}$ & -0.04 & 0.63 & 0.88 & 0.57 \\
\hline
\end{tabular}

with smaller GMT variability (e.g., calibrated for 850-995 CE) perform worse. It is worth noting that the adjusted reconstruction skill for a multiple regression model (Bürger 2007; see appendix for the details) is more inflated during periods of stronger external forcing. The reconstruction skill for GMT variability shows a considerable uncertainty of $0.68 \pm 0.13$ (mean and STD within 21 CALI reconstructions of 10-member ensemble averaged GMT variability) with respect to the choice of calibration period. This finding may explain also the fact that reconstructions perform worse if data are detrended prior to the calibration (e.g., Mann et al. 2007).

To determine the effect of global calibration statistics on LF regional indices including TP, EXT, MDR, and Niño-3 (see section 2a for index definition), we calculate the amount of regional variance that can be explained by GMT variability (unit: \%). This quantity will be referred to as GMT covariance. As expected, the reconstruction skill for regional indices is considerably lower than the GMT reconstruction skill (Table 2). Excluding Niño-3 SST anomalies, the other three reconstructed regional indices (TP, EXP, and MDR) exhibit a high GMT covariance, with a GMT variance fraction exceeding $50 \%$. This finding is consistent with previous studies (Christiansen and Ljungqvist 2017). For the regional indices we also present a relationship between CC_skill, GMT variability, and explained GMT variance for the $21 \mathrm{CALI}$ reconstructions. The results indicate that the reconstruction skill for regional indices depends on the reconstructed GMT amplitude and the relevant GMT covariance. If for a calibration interval the externally forced signal (i.e., GMT variability) is larger compared to the long-term mean level of forced variability, the explained variance of the forced EOF mode of the CFR could increase. This may induce the increasing covariance between GMT and regional-scale variability resulting in a higher score of CC_skill. One exception is the Niño-3 SST reconstruction. Our finding can be explained by the fact that the first leading EOF mode dominates over higher modes in the RegEM algorithm: the first mode calculated for each ensemble member individually represents the internal mode, associated with ENSO and IPO (see Figs. A1 and A2). This is somewhat different from the instrumental leading patterns: the first mode is externally forced mode associated with GMT; the second mode is the leading internal mode. Using a multiproxy network, the real reconstruction by M09 shows only very few degrees of freedom in space with much larger GMT covariance: $92.6 \%$ for TP, $76.2 \%$ for EXT, $83.9 \%$ for MDR, and 5.1\% for Niño-3. M09 suggest that only two spatiotemporal modes are needed to explain the variability prior to $1600 \mathrm{CE}$. The regional features excluding ENSO variability are likely to be characterized by the GMT covariance. In the next section, we will examine the reconstruction skill for past ENSO variability in LF and HF band.

\section{b. Uncertainty in reconstructing tropical Pacific SST variability}

To assess the robustness and uncertainty of the reconstructions for ENSO variability, we compare the Niño-3 variability between original simulation and the pseudoproxy reconstruction using the 1850-1995 CE calibration period (i.e., CALI1850-1995) and random ensemble member (i.e., E10; it has a minimum CC_skill at LF among 10-member ensemble) (Figs. 3a,b). The reconstruction CC_skill amounts to 0.31 and 0.64 for LF and HF ENSO variability, respectively. In addition, we show that the LF tropical Pacific SST variability exhibits larger interensemble and interreconstruction uncertainties compared to the HF ENSO variability (Figs. 3c,d). Even though the reconstruction skill is much higher for the HF 
(a) Nino3_LF, CALI1850-1995, E10, SNR $=0.4$

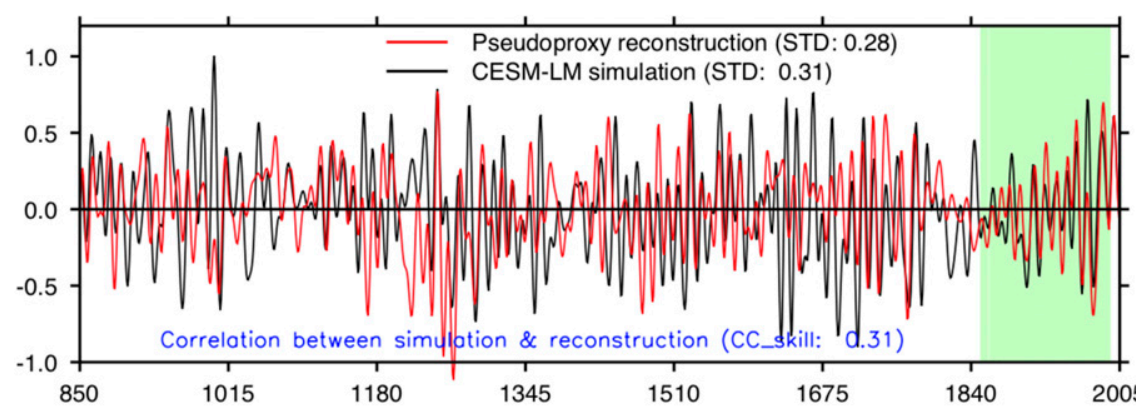

(b) Nino3_HF, CALI1850-1995, E10, SNR = 0.4

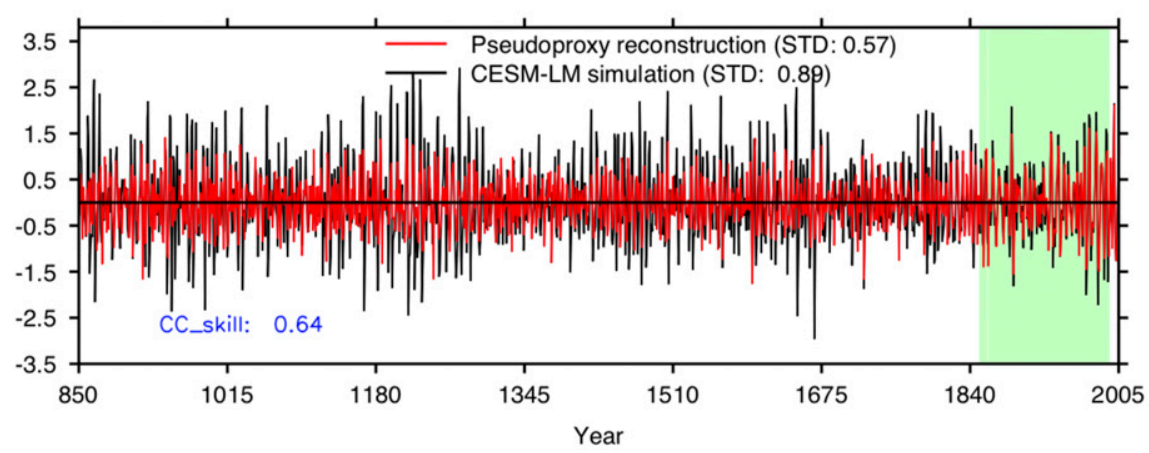

(c) Nino3_LF

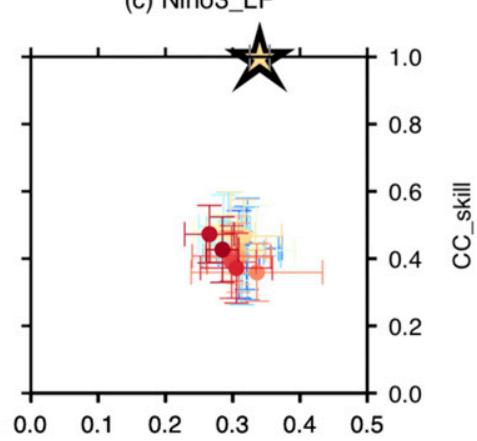

(d) Nino3_HF

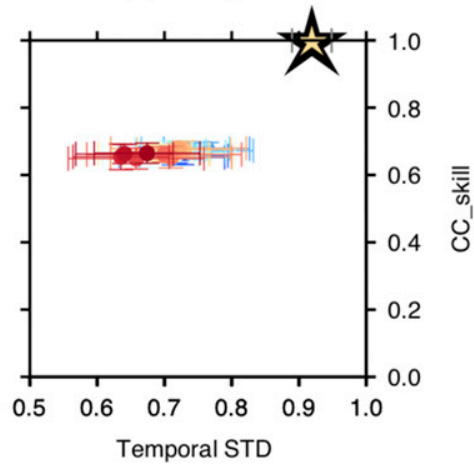

FIG. 3. (a) Low-frequency (10-yr low pass filtered; LF) Niño-3 SST time series in both CESM-LM simulation (black) and pseudoproxy reconstructions (red) with a calibration period of 1850-1995 (CALI1850-1995) and an ensemble member (i.e., E10) from "M09" experiment. Original data are based on yearly averages. The calibration period is highlighted by green shading. (c) Reconstructed LF Niño-3 time series variabilities vs CC_skill for LF Niño-3 time series in 21 individual reconstructions: the mean (filled circle) and interensemble STD (error bar); simulated LF Niño-3 variability (star symbol), in color legend as for Fig. 2. (b), (d) As in (a),(c), but for high-frequency (10-yr high pass filtered; HF) Niño-3 time series.

ENSO band, the amplitude of reconstructed variability (i.e., STD) varies by more than a factor of 2 relative to that of the LF reconstruction. The finding of higher skill for ENSO frequencies is consistent with previous studies (e.g., Braganza et al. 2009; Emile-Geay et al. 2013a; Wilson et al. 2006). For example, Emile-Geay et al. (2013a) suggest that the good performance at ENSO frequencies is due to the fact that for most proxies ENSO variability exhibits enhanced spectral power and higher SNR at interannual periods.

Figure 4 illustrates the fidelity of RegEM in reproducing LF tropical Pacific variability for individual reconstructions (gray lines) and for different calibration periods (different concatenated panels). The original simulation in Fig. 4a exhibits an El Niño-like LF tropical Pacific SST difference between the Medieval Climate Anomaly (MCA; 950-1250 CE) and Little Ice Age (LIA; 1400-1700 CE): the difference is significant at the $95 \%$ confidence level based on a two-tailed Student's $t$ test. The reconstructed 10 -member ensemble mean LF signal (red line) is quite different from the simulated one (black line). For example, the pseudoproxy reconstruction for the CALI1750-1895 (red line in Fig. 4k) fails to reproduce the MCA-LIA cooling trend in the equatorial Pacific: the pseudoproxy reconstruction captures a gradually increasing trend pattern from MCA to modern instrumental era. This indicates that the choice of calibration periods can lead to considerable uncertainties in LF tropical Pacific reconstructions.

Our results document that it is even difficult to reconstruct the 10-member ensemble mean of LF tropical Pacific SST. The skill deteriorates further, if we consider individual ensemble realizations. The frequency histogram for CC_skill values of 210 individual reconstructions (i.e., different combinations of the 10-member ensemble and 21 calibration periods) further illustrates the different reconstruction skills for GMT, LF ENSO, and HF ENSO variabilities (Fig. 5). To characterize the fidelity of the reconstructions, three fit parameters of maximum frequency, center, and full width at half maximum (FWHM) are also obtained from a Gaussian model (Fig. 5). For example, the center of CC_skill values during the entire reconstruction interval (850-2005 CE) is 0.42 for $\mathrm{LF}$ 


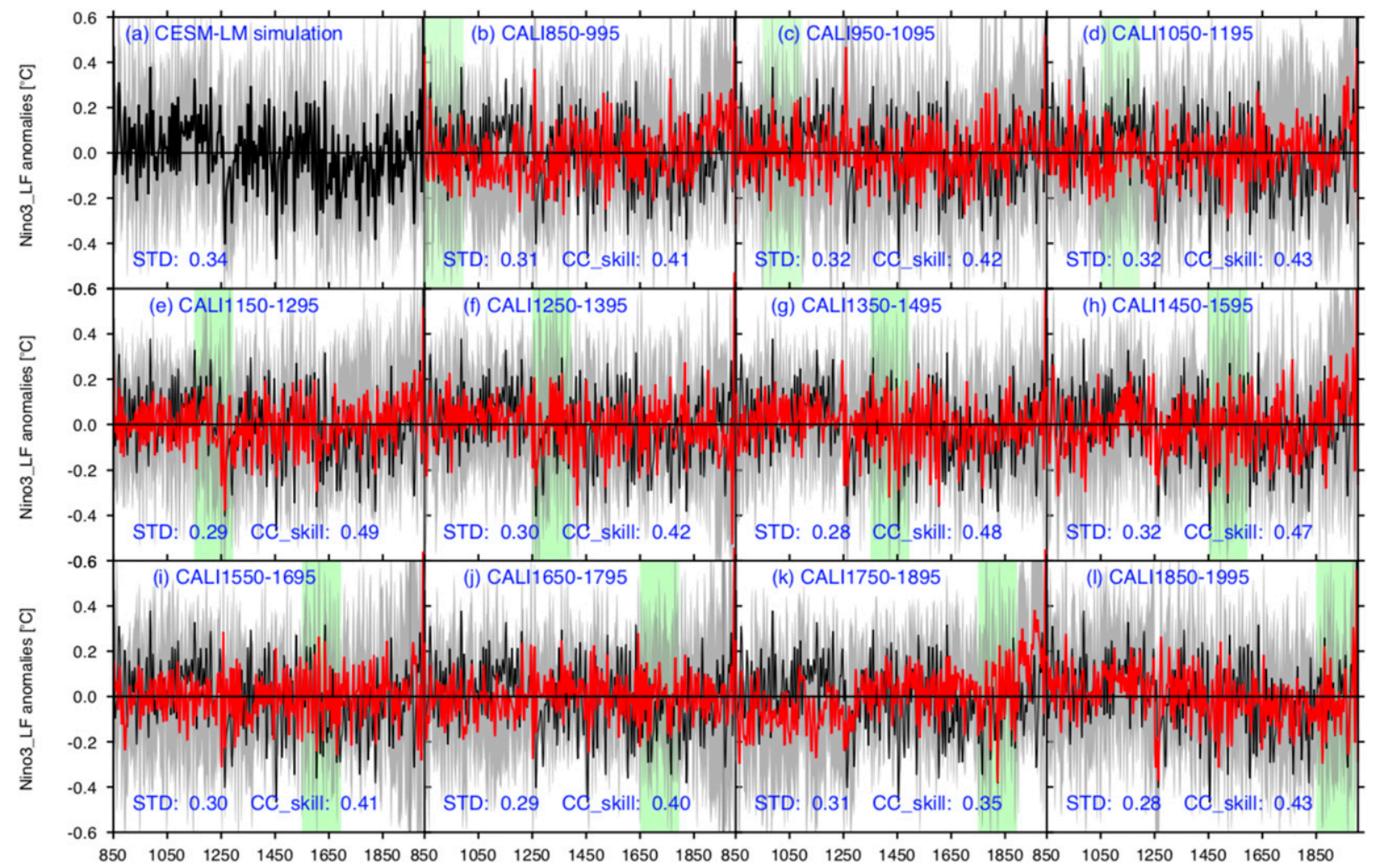

FIG. 4. (a) Simulated LF Niño-3 time series in 10-member ensemble of CESM-LM: the mean (black line) and interensemble STD (gray shading) within 10 member ensemble. (b)-(1) Reconstructed LF Niño-3 time series from "M09" experiment (based on 10-member ensemble and 21 reconstructions with different calibration periods): the mean (red line) and interensemble STD (gray shading) within 10 member of reconstructions; the mean of simulated 10-member ensemble (black line). The vertical green shading denotes the different calibration periods used in the individual pseudoproxy reconstructions.

ENSO, 0.64 for HF ENSO, and 0.75 for GMT, respectively (Fig. 5a). Here we also calculated the reconstruction skills during individual 21 subperiods that are identical to the calibration periods used in CALI reconstructions (Figs. 5b-1). Consistent with Fig. 2, the reconstruction skill for GMT variability varies considerably across different subperiods. The reconstruction has a better (reduced) overall skill and robustness when the subperiod is characterized by larger (weaker) GMT variability (e.g., $1150-1295$ and $1850-1995$ versus 850 995). One of remarkable findings here is that the reconstruction skill for HF ENSO variability is quite stationary. In contrast, the fidelity of LF tropical SST variability is much lower and fluctuates considerably with time (see Fig. $5 \mathrm{~m}$ ).

\section{c. Sensitivity test on reconstruction skill}

The previous section presented evidence for large uncertainties in reconstructing past LF tropical Pacific SSTA variability as well as strong dependence with respect to the choice of the pseudoproxy calibration period. Wang et al. (2014) reported the impact of different noise realizations on the pseudoproxy reconstructions using the RegEM-TTLS method. To further explore the robustness of the reconstructions, we study the impact of different SNR levels on the reconstruction skill for LF and HF ENSO variability (Fig. 6). Pseudoproxy experiments were independently conducted with RegEM for 10 different SNR values covering the range from 0.1 to 1.0. Based on the 210 reconstructions (different combinations of 10-member ensemble and 21 calibration periods), we calculated the frequency histogram for reconstruction skills (i.e., CC_skill) as a function of SNR. The correlation coefficient $(r)$ associated with the SNR can be formulated through $r=\mathrm{SNR} /\left(1+\mathrm{SNR}^{2}\right)^{1 / 2}$ (Mann et al. 2007) (upper $x$ axis in Fig. 6). For example, the SNR of 0.4 used in this study corresponds to $r=0.37$ between noisy proxies and the associated climate signal. It is evident that the CC_skill gradually grows and the spread within the reconstructions decreases as the SNR increases (i.e., as the added noise decreases). Accordingly, the CC_skill for HF ENSO variability (red shading) shows generally better performance than that for LF-ENSO variability (blue shading), for both the entire 
(a) PRD: $850-2005$

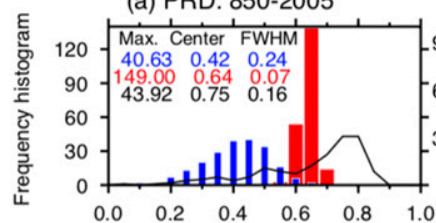

(d) PRD: 1050-1195

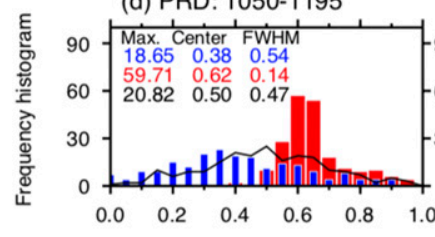

(g) PRD: 1350-1495 (b) PRD: 850-995

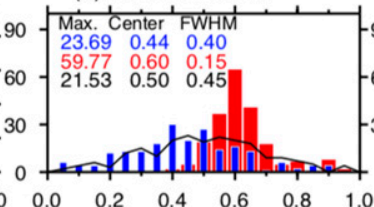

(e) PRD: $1150-1295$

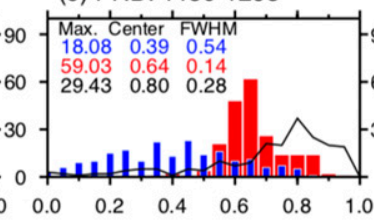

(h) PRD: 1450-1595 (c) PRD: 950-1095

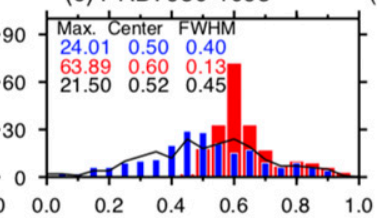

(f) PRD: 1250-1395

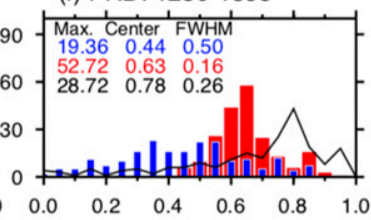

(i) PRD: 1550-1695
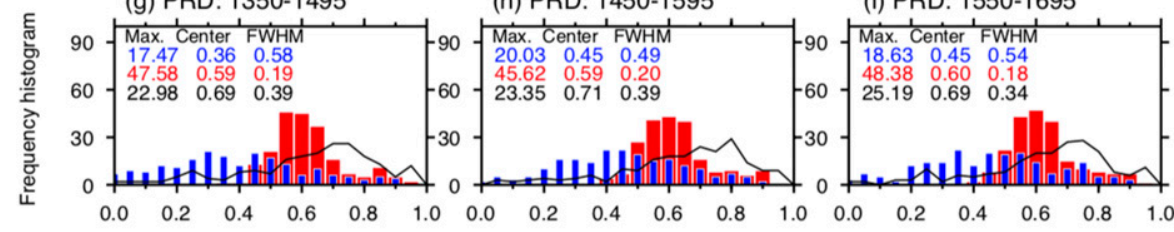

(j) PRD: 1650-1795

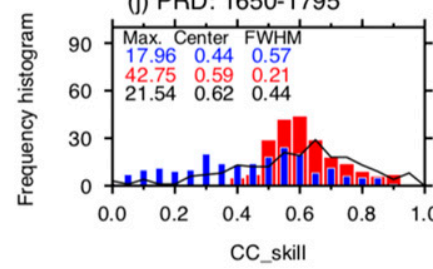

(k) PRD: 1750-1895

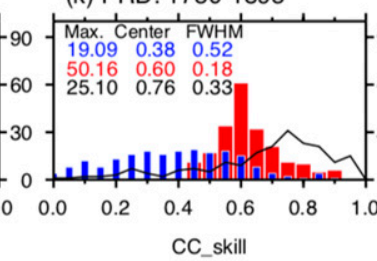

(I)

(I) PRD: 1850-1995

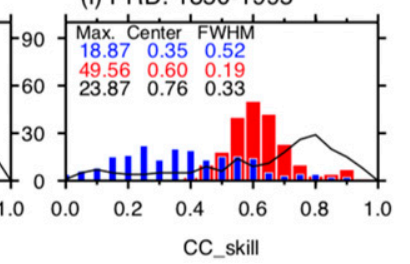

(m) Center\&FWHM in CC_skill statistics

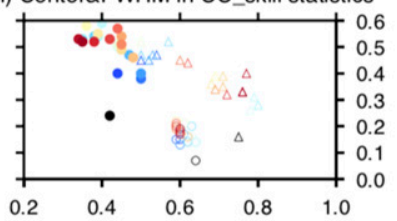

Center

FIG. 5. Frequency histogram for CC_skill statistics of 210 pseudoproxy reconstructions from "M09" experiment in constructing the GMT (black line), and LF Niño-3 (blue bar) and HF Niño-3 (red bar) temperature variability during (a) the period of 850-2005 and (b)-(l) individual 146-yr window subperiods. The CC_skill was respectively calculated on the basis of individual 10 ensemble members and 21 reconstructions with different calibration periods. Three fit parameters of maximum frequency, center, and full width at half-maximum (FWHM) obtained from the Gaussian fitted histogram are displayed in corresponding colored letters. (m) Overview for frequency histograms of center vs FWHM parameters, implying the mean and spread of CC_skill statistics in each histogram.

reconstruction interval as well as individual subperiods considered.

Moreover, we investigate the effect of different proxy networks (EG experiment), hybrid frequency splits (FRE0.1 experiment), different noise levels at HF and LF (DIFFnoise experiment) the CC_skill. The results are compared with the perfect pseudoproxy reconstruction (no added noise, INF experiment) and a pseudoproxy experiment that uses the same parameters and proxy network as in M09 (Table 1). The detailed description for each experiment is provided in Table 1 and section $2 \mathrm{~d}$. Figure 7 summarizes the relative effects of these five pseudoproxy sensitivity experiments on the GMT and ENSO reconstruction skills during the reconstruction interval from 850 to $2005 \mathrm{CE}$. Additionally, we constructed a second low-pass filtered tropical Pacific SST dataset with a 20-yr low-pass cutoff (LF20; e.g., d'Orgeville and Peltier 2007). We can find that the most striking difference of CC_skills between M09 experiment (see section 2d) and the individual four sensitivity experiments appears for the EG and INF experiments. Of particular importance is that the reconstructions for only HF ENSO variability in the EG experiment show higher CC_skill than those in the M09 experiment. This suggests that a reduced, but geographically more targeted proxy network (bottom panel of Fig. 1) can be beneficial for reconstructing regional climate modes, such as ENSO. The CC_skill score for HF ENSO variability in the EG experiment is very similar to that in the INF perfect pseudo experiment. Overall, our analysis here suggests that the improvement in the quality of the proxies (e.g., higher SNR and optimally selected locations) is more important for improving ENSO reconstructions than the increase in number of the proxies, in agreement with the previous studies (e.g., Christiansen and Ljungqvist 2017; Wang et al. 2014).

For the pseudoproxy experiments conducted here, we find that for HF ENSO variability, the median CC_skill values are very high in the vicinity of 0.7 with very low spread within the 210 reconstructions. The median CC_skill for GMT variability also reveals a good 


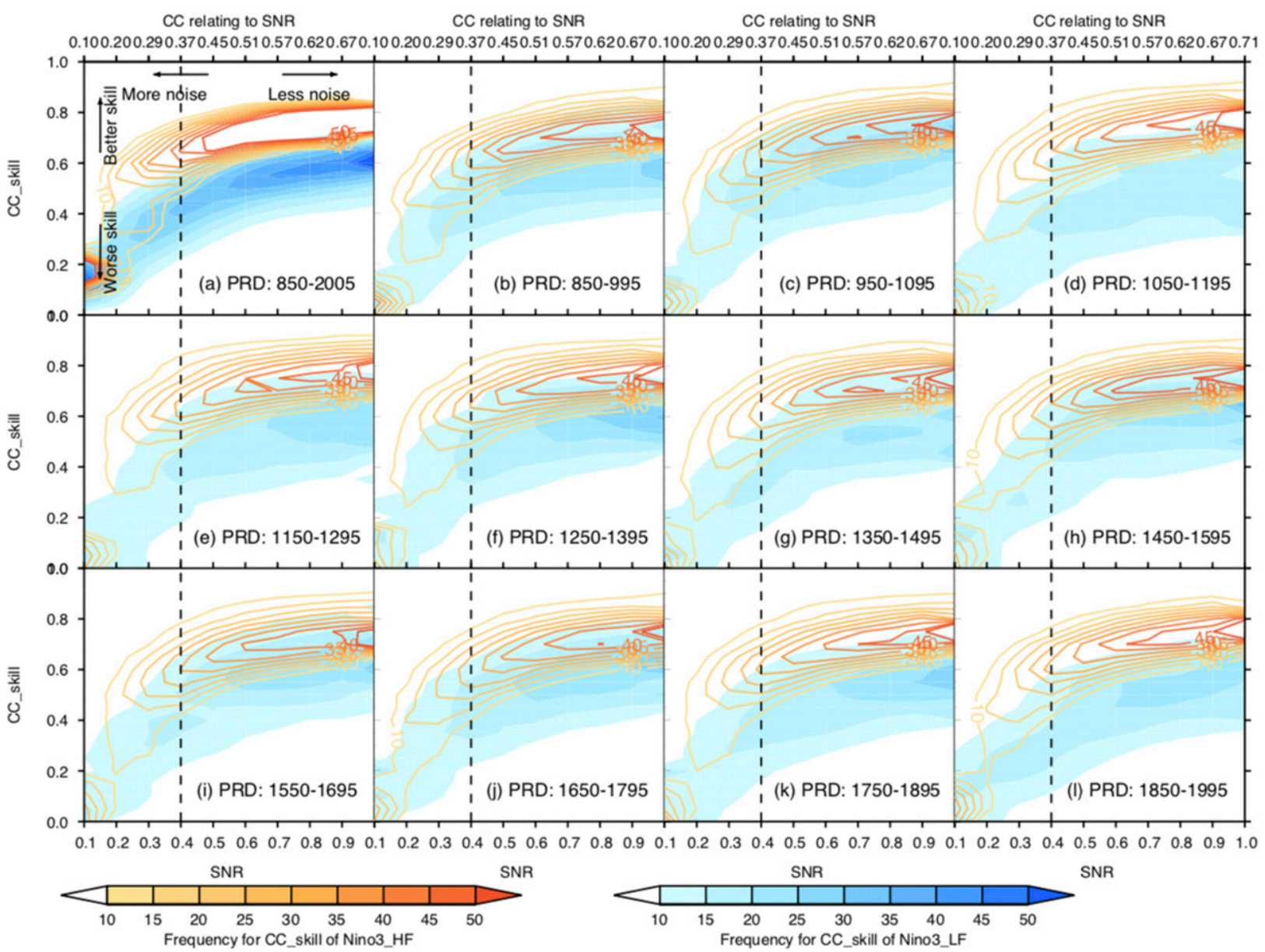

FIG. 6. (a) Two-dimensional frequency histogram of different SNR levels and CC_skill statistics of pseudoproxy reconstructions from "M09" experiment in constructing the LF Niño-3 (blue shading) and HF Niño-3 (red contour) temperature variability during (a) the period of 850-2005 and (b)-(l) individual 146-yr window subperiods. The "M09" experiment is based on 10-member ensemble and 21 reconstructions with different calibration periods: each sample size is 210 . The SNR level of 0.4 used in this study, corresponding to correlation of 0.37 between noise-free pseudoproxies and noise-contaminated pseudoproxies, is denoted by vertical dashed line.

performance $(\sim 0.8)$ but with larger interreconstruction spread depending on the amplitude of GMT variability. The reconstructions for LF20 ENSO variability exhibit considerably reduced median CC_skill compared to the LF ENSO variability case $(\sim 0.3$ for $L F 20 ; \sim 0.5$ for $L F)$. The LF20 case also reveals extremely large interreconstruction spread. This reaffirms the low fidelity of LF tropical Pacific SSTA reconstructions.

\section{Discussion}

Tropical Pacific SST variability is generated by air-sea instabilities, random excitations and as a response to external forcing from greenhouse gases, solar irradiance changes, and volcanic eruptions (e.g., Hope et al. 2017; McGregor and Timmermann 2011; Timmermann et al. 2018; Vecchi and Wittenberg 2010). As the relative ratio of these contributions can change over time, global teleconnections may also become nonstationary. While the paleo data assimilation methods do not assume the stationarity of teleconnection patterns (Hakim et al. 2016), this stationarity is one of assumptions of CFR methods that are based on multivariate regression techniques. It is pivotal to determine the impact of potential nonstationarities on the reconstruction fidelity. To this end we compare the typical ENSO teleconnection pattern during the modern instrumental period (i.e., 1850-1995 CE) with teleconnection patterns during the 21 individual calibration subperiods. Here, the ENSO teleconnection pattern was characterized by the correlation coefficient between the HF Niño-3 SSTA time series and the HF global surface temperature field. Similarly, the IPO patterns for two different time scales (10 and 20 years) were calculated by LF and 


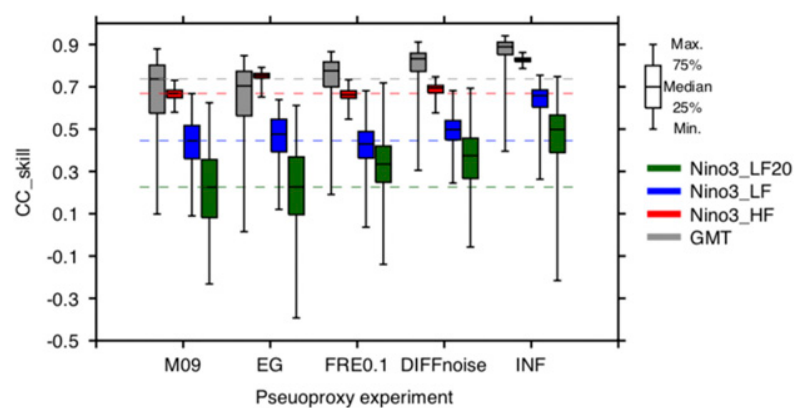

FIG. 7. Box-and-whisker plots (minimum, $25 \%$, median, $75 \%$, and maximum) showing CC_skill statistics of five experiments (see Table 1 for the detail) of pseudoproxy reconstructions in constructing the GMT (black), HF Niño-3 (red), LF Niño-3 (blue), and 20-yr LF Niño-3 (green) temperature variability during the period of 850-2005. Each experiment was conducted in individual 10member ensemble and 21 reconstructions with different calibration periods.

LF20-Niño-3 associated correlation patterns. The frequency histogram of pattern correlation coefficients between individual subperiod ENSO teleconnections and the modern ENSO teleconnection is considered for 210 samples ( 21 subperiods $\times 10$ ensemble) in the CESM-LM simulation and 4410 samples (21 subperiods $\times 210$ CALI reconstructions) for the pseudoproxy reconstruction datasets (Figs. 8a,b).

The figure indicates that the simulated ENSO teleconnection patterns remain relatively stationary over time, in agreement with previous studies (Coats et al. 2013; D'Arrigo et al. 2005; Lewis and LeGrande 2015; Yun and Timmermann 2018), whereas the IPO patterns exhibit a much larger degree of nonstationarity (see Fig. 8a). This nonstationarity arises from the fact that the relative contributions of internal and externally forced LF tropical SST variability vary in time. As noted in Coats et al. (2013), the models' characteristics (e.g., amplitude, autocorrelation, and phase) in simulating ENSO variability can affect the multidecadal changes of the IPO patterns, which will be examined in a future study. The stationarity of the ENSO pattern explains why the HF reconstruction skill is considerably larger than the LF reconstruction skill. Moreover, we propose that the robustness of HF ENSO teleconnections is due the fact that ENSO arises mostly from internal climate instabilities. The effect of external forcing on interannual SST variability in the tropical Pacific is small. In contrast, the LF IPO (i.e., multidecadal variability of ENSO) appears to be more affected by external forcing (e.g., Hope et al. 2017), thereby creating a stronger dependency with respect to the calibration period and exhibiting larger nonstationarity (Wilson et al. 2010; Yeh et al. 2018). (a) CESM-LM simulation

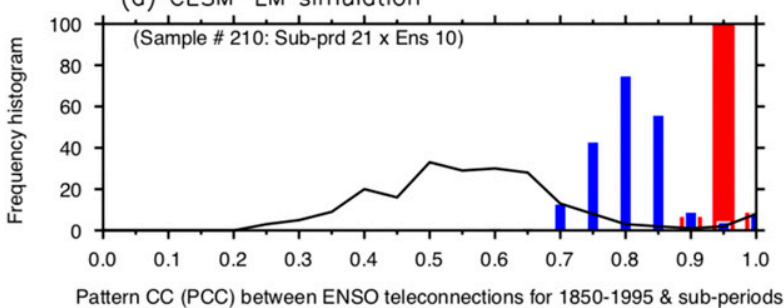

(b) Pseudo-proxy reconstruction, SNR $=0.4$

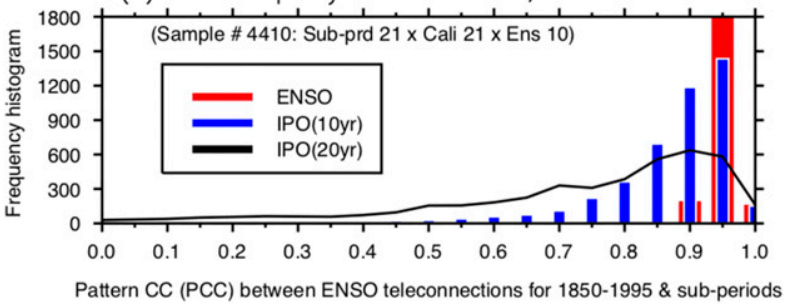

FIG. 8. Frequency histogram for pattern CC (PCC) between ENSO teleconnections for the years 1850-1995 and the years of each subperiod (i.e., identical to calibration periods used) in 10-member ensemble of both (a) CESM-LM simulation (sample number is 21 subperiods $\times 10$ ensemble) and (b) pseudoproxy reconstructions from "M09" experiment (sample number is 21 subperiods $\times 10$ ensemble $\times 21$ calibration cases): ENSO (HF Niño-3 correlated; red bar), IPO (LF Niño-3 correlated; blue bar), and IPO (20-yr LF Niño-3 correlated; black line) patterns. ENSO (IPO) patterns were diagnosed as the correlation between HF (LF) Niño-3 time series and HF (LF) surface temperature field, respectively.

The low fidelity of reconstructed LF ENSO variability can be affected by the method used for the reconstruction (e.g., Smerdon et al. 2016; Wang et al. 2015). To further examine whether other statistical formulations might improve the reconstruction skill for LF ENSO variability, we performed several pseudoproxy reconstructions using three additional RegEM variants: 1) RegEM-Ridge regression (Fig. 9a), 2) nonhybrid RegEM-TTLS (originally used in Schneider (2001; Fig. 9b), and 3) nonhybrid RegEM-TTLS but with a fixed truncation parameter of 50 (resolving $90 \%$ of the data variance; Fig. 9c). For RegEM-Ridge, the ridge regression parameter is determined by minimization of the generalized cross validation (GCV) function. The reconstruction skill statistics are presented for every single ensemble member on the basis of 21 reconstructions for different calibration periods. Larger spread in CC_skills is associated with greater calibration dependency of the pseudoproxy reconstructions. Overall, the reconstruction scores obtained by using the Ridge regression (Fig. 9a) and choosing higher truncation parameter $M$ (Fig. 9c) are lower than those obtained for both hybrid and nonhybrid RegEM-TTLS (Figs. 9b,d). This result is consistent with previous studies (Mann et al. 2007; Rutherford et al. 2010). Although the 
(a) RegEM-Ridge
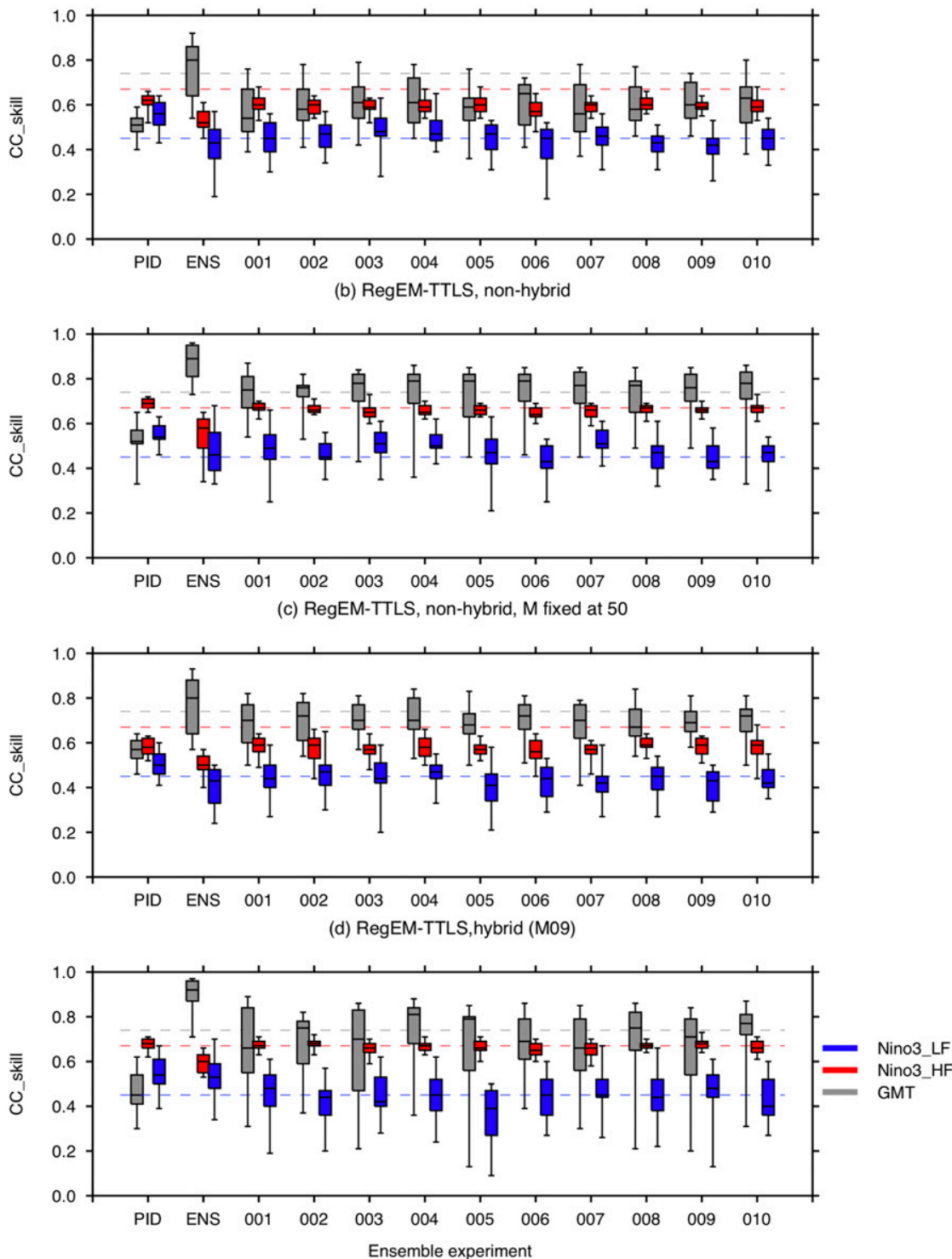

FIG. 9. Box-and-whisker plots (minimum, 25\%, median, 75\%, and maximum) showing each ensemble CC_skill statistic of pseudoproxy reconstructions in constructing the GMT (black), HF Niño-3 (red), and LF Niño-3 (blue) temperature variability during the period of 850-2005, based on different reconstruction methods: (a) RegEM-Ridge, (b) nonhybrid RegEM-TTLS, (c) nonhybrid RegEM-TTLS with a fixed truncation parameter $(M)$ at 50, and (d) hybrid RegEM-TTLS (i.e., same as M09). Two pseudoproxy reconstructions using 10-member ensemble mean (i.e., ENS) and one member PID were also conducted to test the different levels of externally forced variability. The statistics in each ensemble is based on 21 reconstructions with different calibration periods. The colored dash lines indicate the median values from M09 experiment of Fig. 7.

calibration dependency in M09 (Fig. 9d) is somewhat larger than those in other methods (Figs. 9a-c), all reconstructions reveal better reconstruction skills in HF ENSO variability than for the LF variability. This indicates that within the RegEM framework, the low fidelity of LF ENSO reconstructions is not a result of the methodologies applied. More examinations using other CFR techniques (e.g., CCA and Gaussian graphical models) will be needed to further determine the robustness of the methods. 

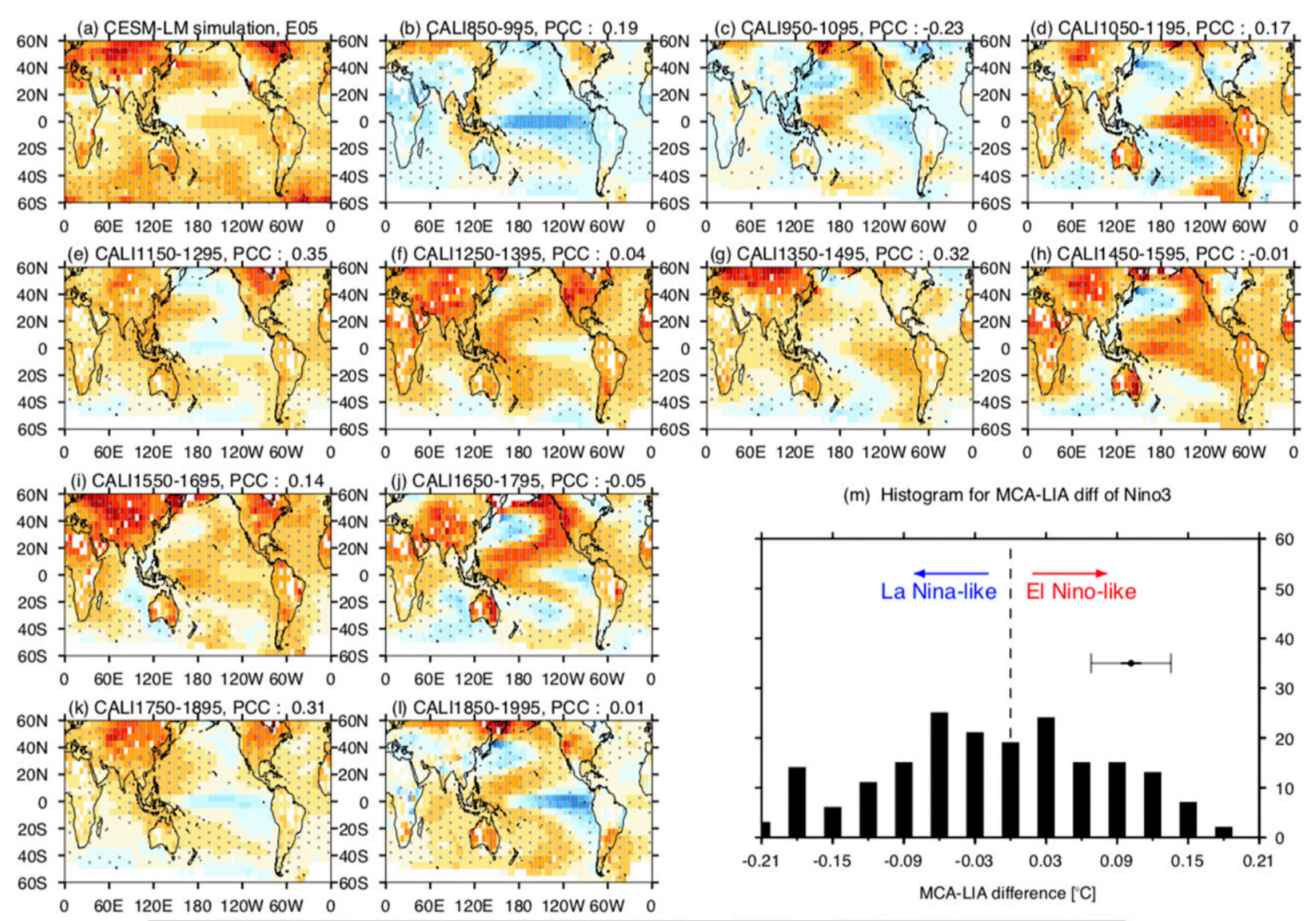

(m) Histogram for MCA-LIA diff of NinO3

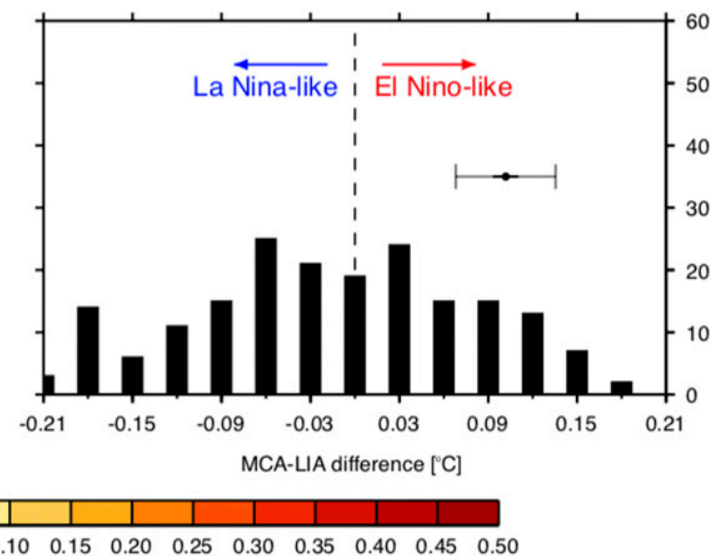

FIG. 10. Spatial differences of surface temperature anomalies between Medieval Climate Anomaly (MCA; 950-1250 CE) and Little Ice Age (LIA; 1400-1700 CE) in an ensemble member (i.e., E05) of both (a) CESM-LM simulation and (b)-(1) pseudoproxy reconstructions with different calibration periods from "M09" experiment. The dot indicates the area where the difference is significant at the $95 \%$ confidence level. The PCC in right side of each panel indicates the pattern correlation between simulated and reconstructed temperature differences between MCA and LIA. (m) Frequency histogram for the 210 reconstructed Niño-3 temperature differences between MCA and LIA (i.e., in individual 10-member ensemble and 21 reconstructions with different calibration periods). The dot and horizontal error bar indicate the mean of simulated Niño-3 MCA-LIA differences and interensemble STD within 10-member. The El Niño-like MCALIA difference in CESM-LM simulation is significant at the 95\% confidence level, based on a two-tailed Student's $t$ test.

The modeled background state and the model's sensitivity to external forcing may also affect the reconstruction skill for the LF tropical Pacific SST variability (Smerdon et al. 2016). To present the different levels of externally forced variability, we conducted two pseudoproxy reconstructions using the 10 -member ENS and one member of an unforced preindustrial control simulation. Comparing the resulting pseudoproxy reconstructions, we find that the reconstruction skill for LF tropical SST is larger in the preindustrial control simulation (PID) experiment than in ENS and even each individual ensemble member experiment (see Fig. 9). Another point to note is that in the externally forced simulation the skill score of HF ENSO drops considerably, which is in sharp contrast to the much higher skill in GMT. This reaffirms that the reconstruction performance for HF and LF ENSO is quite sensitive to the level of externally forced variability and seems to be less dependent on the RegEM CFR methodology.

We next demonstrate how the calibration uncertainty can affect the covariance-based CFR for past climate episodes. Figures 10b-i show the spatial differences of reconstructed temperature anomalies between MCA and LIA using the original CESM-LM simulation (Fig. 10a) and employing different calibration periods. For better illustration we show the surface temperature anomaly patterns for only one ensemble member (i.e., E05). We can see that the field reconstructions vary considerably for different calibration periods (pattern CC_skills are almost less than 0.3): for example, the 
CALI850-995 reconstruction reveals a "La Niña-like" pattern but for the CALI1850-1995 we find an "El Niño-like" pattern between MCA and LIA. The same analysis has been also conducted for the remaining 9 ensemble members. The marked discrepancy across the reconstructions is further highlighted by the frequency distribution of Niño-3 SSTA differences between MCA and LIA for the individual 210 calibration periods and the 10 ensemble members (Fig. 10m). The original simulated El Niño-like change is captured in only $50 \%$ (104) of the reconstructions, whereas the opposite La Niña-like change accounts also for $\sim 50 \%$ (106) of reconstructions. As has been suggested previously, the reconstructed spatial patterns tend to be method and model dependent (e.g., Smerdon et al. 2016; Wang et al. 2015). Therefore, the La Niña-like MCA-LIA pattern shown in the real-proxy reconstruction of M09 has not been reproduced by some CFR methods and is inconsistent with most of the LM simulations conducted with CGCMs. In fact, there is still an extensive discussion regarding the dynamic implications of a potential La Niña-like MCA-LIA pattern (e.g., Cook et al. 2016). Although several studies (e.g., Mann et al. 2005b) suggested that the positive tropical radiative forcing (i.e., high solar irradiance and inactive tropical volcanism) may even lead to a La Niña-like response, most models forced by the radiative forcing do not produce the anomalous cool eastern Pacific during the MCA. Furthermore, evidence from hydrological and temperature proxy data also reveals no significant difference in ENSO behavior between MCA and LIA (Henke et al. 2017). Christiansen et al. (2009) demonstrated that the divergent reconstruction results are to some extent caused by the stochasticity of the climate system and the way it is accounted for in different CFR methods. Here, we conclude further that the documented uncertainties in reconstructions can be traced back to the nonstationarity of LF tropical SST variability and the time-varying contributions from internal and external variability.

\section{Summary and conclusions}

Our study provided an in-depth analysis of the uncertainties that arise in reconstructions of past tropical Pacific climate variability. To this end we performed a large number of pseudoproxy experiments with a special focus on different calibration periods. The pseudoproxy experiments were based on simulated surface temperature anomalies from a 10-member ensemble of CESMLM simulations covering the period from 850 to 2005 CE. Our study was motivated by the restrictive assumption of most covariance-based CFR methods that the leading patterns of variability during the instrumental observation period remain stationary. We applied the RegEM CFR algorithm following the procedure of M09 (and variant thereof) and performed pseudoproxy experiments on the basis of the 146-yr window calibration period sliding from the period 850-995 CE to 1850-1995 CE, with a 50-yr time lag.

The pseudoproxy reconstructions for tropical Pacific SSTA exhibit considerable interensemble and inter-CALI reconstruction differences. Our study identifies a strong relationship between amplitude of reconstructed GMT variabilities and reconstruction skill for different calibration periods. Reconstructions with larger GMT variability tend to have a better skill performance for GMT and regional climate indices. Consistent with previous studies, we find that reconstructions of HF (interannual) ENSO variability are very skillful with correlations of $\sim 0.7$, and little difference between the simulation and reconstructions. In contrast, IPO variability is reconstructed less faithfully. These results are further confirmed by a series of sensitivity experiments that use different proxy networks, hybrid frequency split, and different SNR levels. HF ENSO is generated mainly by internal dynamical processes. In contrast, LF tropical SST variability is likely to be affected by a combination of external forcing and internal processes. We further demonstrate that the combined and timevarying impact of external forcing and internal variability of ENSO may induce nonstationarity of teleconnection patterns over time, which in turn reduce the fidelity of the RegEM-based reconstruction. Finally, in addition to the model and method dependency documented for reconstructions of the MCA-LIA SST pattern (e.g., Smerdon et al. 2016; Wang et al. 2015), our study further demonstrates a strong dependency on the statistics of the calibration period, indicating that the La Niña-like MCAto-LIA pattern reconstructed with real-proxy data (e.g., M09) may be more uncertain than previously suggested.

Calibration proxy data against the twentieth-century no-analog situation introduce higher reconstruction skill for GMT ( $\sim 0.79$ on average) compared to other calibration periods $(\sim 0.68$; the difference is significant at the $95 \%$ confidence level). However, the improved GMT skill does not translate to better regional reconstruction skills. For example, the HF ENSO in the ENSbased reconstruction shows the minimum skill score within the 21 reconstructions. Clearly, regional-scale reconstructions derived from the twentieth-century calibration interval are associated with large uncertainties. To overcome this issue, we recommend considering ensemble calibration techniques that are similar to methods that apply different calibration lengths (Frank et al. 2010). Another approach is to generate surrogate instrumental fields (Christiansen 2011; Christiansen et al. 2009). We further suggest that 

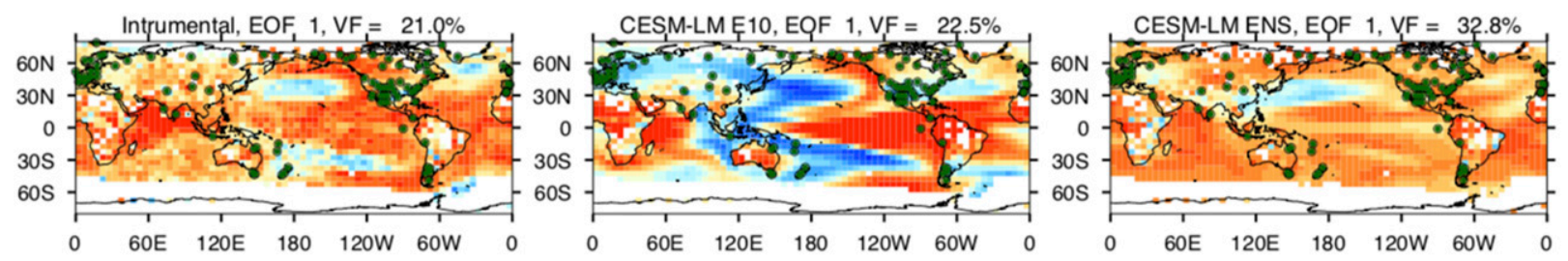

Intrumental, EOF, $2, V F=10.2 \%$
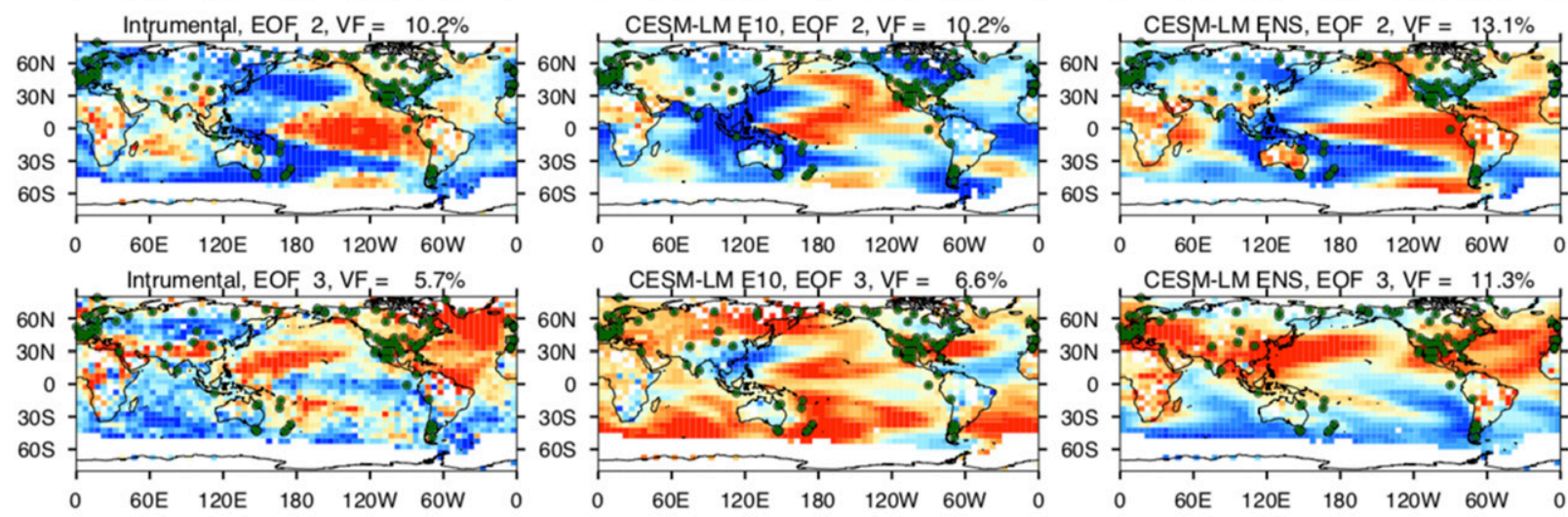

CESM-LM E10, EQF 3, VF = $6.6 \%$
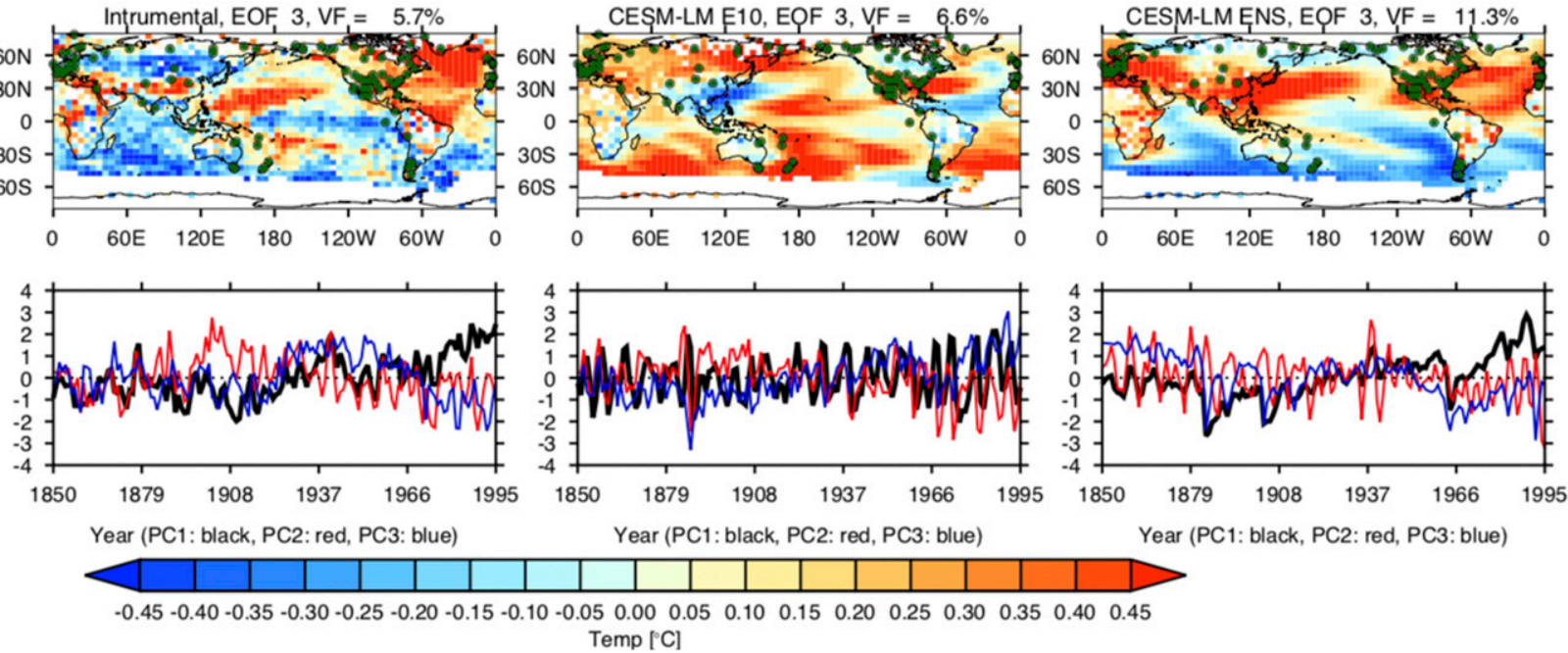

FIG. A1. Spatial patterns and corresponding PC time series of the first three leading modes of annual surface temperature anomalies during 1850-1995: (left) instrumental observation, (middle) CESM-LM simulation for an ensemble member (i.e., E10), and (right) CESM-LM simulation for 10-member ensemble mean (i.e., ENS). VF indicates the explained variance fraction of the EOFs. The pseudoproxy locations are denoted by green dots.

the ensemble of reordered instrumental fields can represent different low-frequency trends and resultant different levels of externally forced variability. This ensemble approach could further reduce or help quantify calibration uncertainties. Last, more reliable paleo-proxy data from key locations as well as improved climate models will give a better understanding of the drivers of lowfrequency variability during the LM.

Acknowledgments. This study was supported by a 2-Year Research Grant of Pusan National University.

\section{APPENDIX}

\section{Stationary Assumption on the Leading Pattern}

The instrumental data (i.e., $X_{i, s}$, “ $i$ " instrumental time; " $s$ " instrumental spatial grids) can be expressed by

$$
X_{i, s}=\sum_{L=1}^{M} \lambda_{L} X_{\mathrm{PC}_{i, L}} X_{\mathrm{EOF}_{s, L}}
$$

where $\lambda_{L}, X_{\mathrm{EOF}_{s, L}}$, and $X_{\mathrm{PC}_{i, L}}$ refer to the eigenvalue, eigenvector, and the corresponding principal component time series (PC), respectively; $M$ is the EOF mode number $(L)$ retained in RegEM algorithm. The covariance matrix both within and between the standardized proxy ( $Y_{j, m}$, " $j$ " proxy time; " $m$ " proxy locations) and instrumental $\left(X_{\mathrm{PC}_{i, L}}\right)$ data is estimated through the RegEM formula [Eq. (1) in Mann et al. (2007)] and $\hat{Y}_{\mathrm{PC}_{j, L}}$ is then predicted. The predictand (i.e., $\hat{Y}_{j, s}$ ) is finally reconstructed by using the instrumental EOF patterns (i.e., $X_{\mathrm{EOF}_{s, L}}$ ).

$$
\hat{Y}_{j, s}=\sum_{L=1}^{M} \lambda_{L} \hat{Y}_{\mathrm{PC}_{j, L}} X_{\mathrm{EOF}_{s, L}}
$$



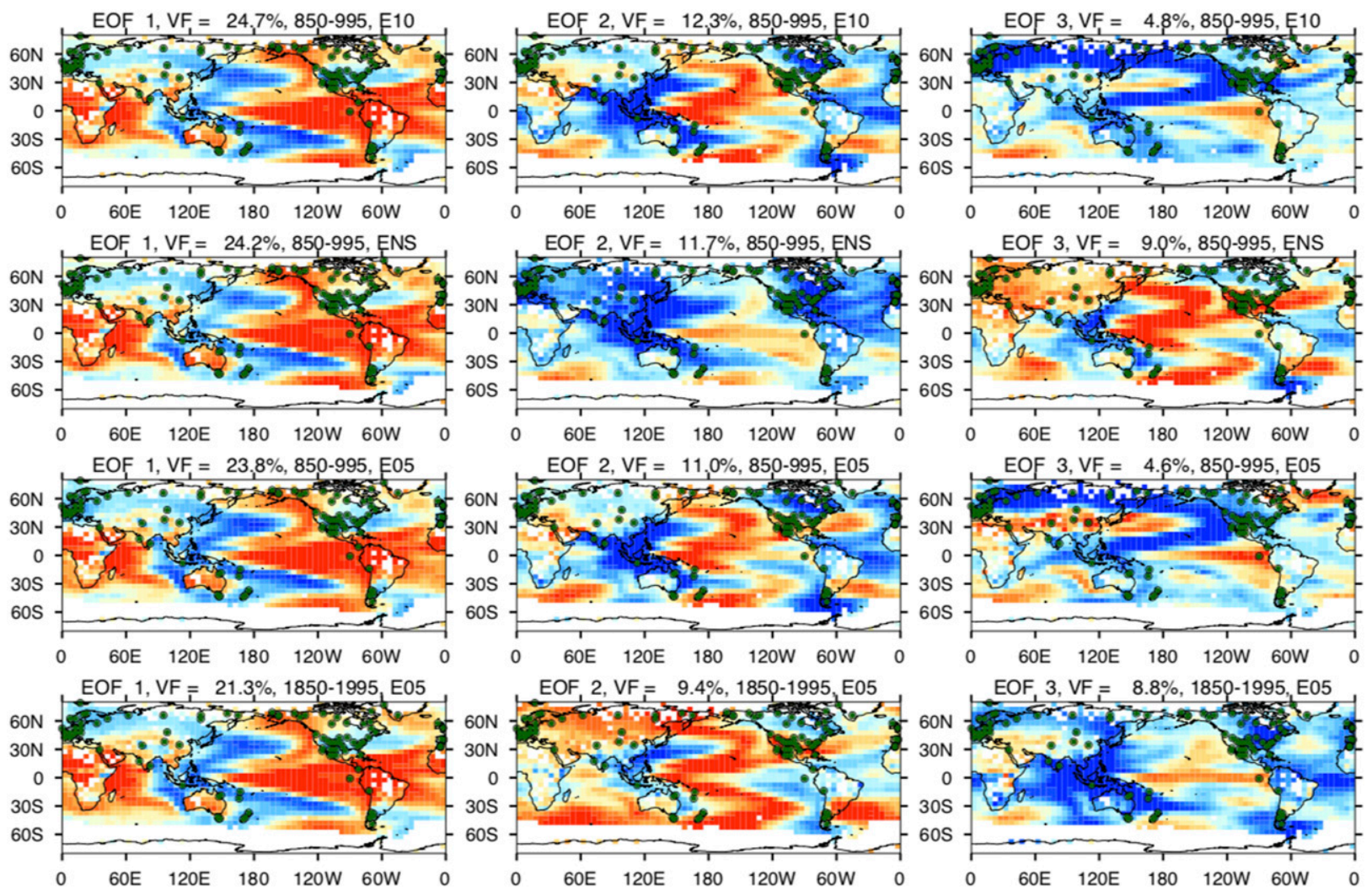

FIG. A2. Spatial patterns of the first three leading modes of CESM-LM simulated annual surface temperature anomalies: (first row) an ensemble E10 during 850-995 CE, (second row) ensemble mean (ENS) during 850-995 CE, (third row) an ensemble E05 during 850-995 $\mathrm{CE}$, and (fourth row) an ensemble E05 during 1850-1995 CE. VF indicates the explained variance fraction of the EOFs. The pseudoproxy locations are denoted by green dots.

Therefore, the leading patterns of variability remain stationary through the reconstruction. We put a special focus on the leading pattern of low-frequency variability, because the pattern of low-frequency variability could be much more affected by the transient external forcing than that of high-frequency variability does. Even though the reconstructions are constructed by summing up the retained EOFs, the relative ratio of the contributions between external and internal modes might change in time and this can generate considerable uncertainties in reconstructions.

Here, we present the first three leading modes obtained from some ensembles of CESM-LM simulation (Figs. A1 and A2). The comparison of the EOF patterns between the periods 1850-1995 and 850-995 CE reveals that the patterns in CESM-LM simulation vary with time and the change is particularly significant in those obtained from the ENS: The explained variance of the low-frequency global warming pattern decreases drastically prior to the twentieth century. This challenges the stationary assumption on leading patterns of lowfrequency variability.

\section{True reconstruction skill}

Following Bürger (2007), we calculated the true reconstruction skills as function of the adjusted coefficient of determination $\left(\overline{R^{2}}\right)$. The $\overline{R^{2}}$ can determine how well a

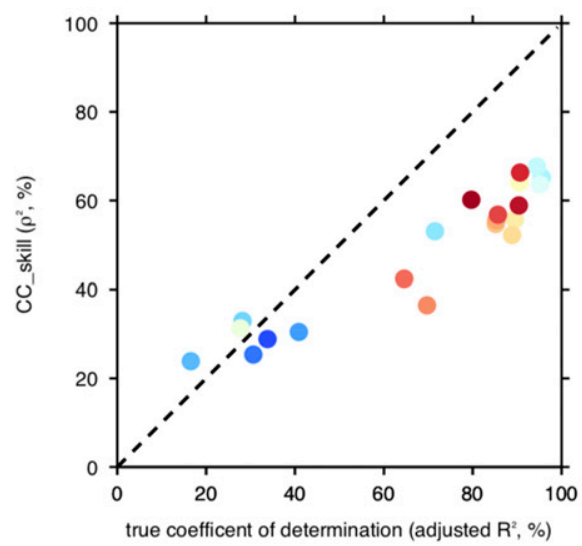

- CALI1850-1995
CALI1800-1945
CALI1750-1895
CALI1700-1845
CALI1650-1795
CALI1600-1745
CALI1550-1695
CALI1500-1645
CALI1450-1595
CALI1400-1545
CALI1350-1495
CALI1300-1445
CALI1250-1395
CALI1200-1345
CALI1150-1295
CALI1100-1245
CALI1050-1195
- CALI1000-1145
CALI950-1095
- CALI900-1045
- CALI850-995

FIG. A3. Relationship between the adjusted coefficient of determination (adjusted $R^{2}$ ) and CC_skill $\left(\rho^{2}\right)$ for GMT variability. The coefficients averaged for the 10 -member ensemble are displayed in each calibration reconstruction. 
multiple regression model fits the sample data, relative to the coefficient of determination $\left(R^{2}\right)$ for a simple regression model. The $R^{2}$ can be adjusted as follows:

$$
\overline{R^{2}}=1-\left(1-R^{2}\right) \frac{N-1}{N-p-1},
$$

where $N$ is years of calibration (i.e., $N=146$ ) and $p$ is number of proxies (i.e., $p=104$ ). The correlation coefficient between the reconstruction and simulation during 850-2005 CE $\rho$ was compared to the adjusted coefficient of determination in Fig. A3. We can find that the reconstruction skill is somewhat inflated because of the presence of strong external forcing during the calibration period.

\section{REFERENCES}

Adams, J. B., M. E. Mann, and C. M. Ammann, 2003: Proxy evidence for an El Niño-like response to volcanic forcing. Nature, 426, 274-278, https://doi.org/10.1038/nature02101.

Anchukaitis, K. J., and Coauthors, 2017: Last millennium Northern Hemisphere summer temperatures from tree rings: Part II, spatially resolved reconstructions. Quat. Sci. Rev., 163, 1-22, https://doi.org/10.1016/j.quascirev.2017.02.020.

Braganza, K., J. L. Gergis, S. B. Power, J. S. Risbey, and A. M. Fowler, 2009: A multiproxy index of the El Niño-Southern Oscillation, A.D. 1525-1982. J. Geophys. Res., 114, D05106, https://doi.org/10.1029/2008JD010896.

Brohan, P., J. J. Kennedy, I. Harris, S. F. Tett, and P. D. Jones, 2006: Uncertainty estimates in regional and global observed temperature changes: A new data set from 1850. J. Geophys. Res., 111, D12106, https://doi.org/10.1029/2005jd006548.

Bürger, G., 2007: On the verification of climate reconstructions. Climate Past, 3, 397-409, https://doi.org/10.5194/cp-3-3972007.

- and U. Cubasch, 2005: Are multiproxy climate reconstructions robust? Geophys. Res. Lett., 32, L23711, https:// doi.org/10.1029/2005gl024155.

Christiansen, B., 2011: Reconstructing the NH mean temperature: Can underestimation of trends and variability be avoided? J. Climate, 24, 674-692, https://doi.org/10.1175/2010JCLI3646.1. , and F. C. Ljungqvist, 2017: Challenges and perspectives for large-scale temperature reconstructions of the past two millennia. Rev. Geophys., 55, 40-96, https://doi.org/10.1002/ 2016RG000521.

—, T. Schmith, and P. Thejll, 2009: A surrogate ensemble study of climate reconstruction methods: Stochasticity and robustness. J. Climate, 22, 951-976, https://doi.org/10.1175/ 2008JCLI2301.1.

Coats, S., J. E. Smerdon, B. I. Cook, and R. Seager, 2013: Stationarity of the tropical Pacific teleconnection to North America in CMIP5/PMIP3 model simulations. Geophys. Res. Lett., 40, 4927-4932, https://doi.org/10.1002/grl.50938.

, — - B. Cook, R. Seager, E. R. Cook, and K. Anchukaitis, 2016: Internal ocean-atmosphere variability drives megadroughts in Western North America. Geophys. Res. Lett., 43, 9886-9894, https://doi.org/10.1002/2016GL070105.

Cook, B. I., E. R. Cook, J. E. Smerdon, R. Seager, A. P. Williams, S. Coats, D. W. Stahle, and J. Villanueva Díaz, 2016: North
American megadroughts in the Common Era: Reconstructions and simulations. Wiley Interdiscip. Rev.: Climate Change, 7, 411-432, https://doi.org/10.1002/wcc.394.

D’Arrigo, R., E. R. Cook, R. J. Wilson, R. Allan, and M. E. Mann, 2005: On the variability of ENSO over the past six centuries. Geophys. Res. Lett., 32, L03711, https://doi.org/10.1029/ 2004 gl022055.

d'Orgeville, M., and W. R. Peltier, 2007: On the Pacific decadal oscillation and the Atlantic multidecadal oscillation: Might they be related? Geophys. Res. Lett., 34, L23705, https:// doi.org/10.1029/2007gl031584.

Emile-Geay, J., K. M. Cobb, M. E. Mann, and A. T. Wittenberg, 2013a: Estimating central equatorial Pacific SST variability over the past millennium. Part I: Methodology and validation. J. Climate, 26, 2302-2328, https://doi.org/10.1175/jcli-d-1100510.1 .

,,,--- and $-2013 \mathrm{~b}$ : Estimating central equatorial Pacific SST variability over the past millennium. Part II: Reconstructions and implications. J. Climate, 26, 2329-2352, https://doi.org/10.1175/JCLI-D-11-00511.1.

Esper, J., D. C. Frank, R. J. Wilson, and K. R. Briffa, 2005: Effect of scaling and regression on reconstructed temperature amplitude for the past millennium. Geophys. Res. Lett., 32, L07711, https://doi.org/10.1029/2004gl021236.

Evans, M. N., A. Kaplan, and M. A. Cane, 2002: Pacific sea surface temperature field reconstruction from coral $\delta^{18} \mathrm{O}$ data using reduced space objective analysis. Paleoceanography, 17, 1007 , https://doi.org/10.1029/2000pa000590.

- J. E. Smerdon, A. Kaplan, S. Tolwinski-Ward, and J. González-Rouco, 2014: Climate field reconstruction uncertainty arising from multivariate and nonlinear properties of predictors. Geophys. Res. Lett., 41, 9127-9134, https://doi.org/ 10.1002/2014GL062063.

Fernández-Donado, L., and Coauthors, 2013: Large-scale temperature response to external forcing in simulations and reconstructions of the last millennium. Climate Past, 9, 393-421, https://doi.org/10.5194/cp-9-393-2013.

Frank, D. C., J. Esper, C. C. Raible, U. Büntgen, V. Trouet, B. Stocker, and F. Joos, 2010: Ensemble reconstruction constraints on the global carbon cycle sensitivity to climate. $\mathrm{Na}$ ture, 463, 527-530, https://doi.org/10.1038/nature08769.

Gao, C., A. Robock, and C. Ammann, 2008: Volcanic forcing of climate over the past 1500 years: An improved ice core-based index for climate models. J. Geophys. Res., 113, D23111, https://doi.org/10.1029/2008jd010239.

Goosse, H., E. Crespin, A. de Montety, M. Mann, H. Renssen, and A. Timmermann, 2010: Reconstructing surface temperature changes over the past 600 years using climate model simulations with data assimilation. J. Geophys. Res., 115, D09108, https://doi.org/10.1029/2009jd012737.

Guillot, D., B. Rajaratnam, and J. Emile-Geay, 2015: Statistical paleoclimate reconstructions via Markov random fields. Ann Appl. Stat., 9, 324-352, https://doi.org/10.1214/14-AOAS794.

Hakim, G. J., J. Emile-Geay, E. J. Steig, D. Noone, D. M. Anderson, R. Tardif, N. Steiger, and W. A. Perkins, 2016: The last millennium climate reanalysis project: Framework and first results. J. Geophys. Res. Atmos., 121, 6745-6764, https:// doi.org/10.1002/2016jd024751.

Henke, L. M., F. H. Lambert, and D. J. Charman, 2017: Was the Little Ice Age more or less El Niño-like than the Medieval Climate Anomaly? Evidence from hydrological and temperature proxy data. Climate Past, 13, 267-301, https://doi.org/ 10.5194/cp-13-267-2017. 
Hope, P., B. J. Henley, J. Gergis, J. Brown, and H. Ye, 2017: Timevarying spectral characteristics of ENSO over the Last Millennium. Climate Dyn., 49, 1705-1727, https://doi.org/ 10.1007/s00382-016-3393-z.

Lewis, S., and A. LeGrande, 2015: Stability of ENSO and its tropical Pacific teleconnections over the Last Millennium. Climate Past, 11, 1347-1360, https://doi.org/10.5194/cp-111347-2015.

Li, J., and Coauthors, 2013: El Niño modulations over the past seven centuries. Nat. Climate Change, $\mathbf{3}, 822$, https://doi.org/ 10.1038/nclimate1936.

Mann, M. E., R. S. Bradley, and M. K. Hughes, 1998: Global-scale temperature patterns and climate forcing over the past six centuries. Nature, 392, 779-787, https://doi.org/10.1038/ 33859 .

_, S. Rutherford, E. Wahl, and C. Ammann, 2005a: Testing the fidelity of methods used in proxy-based reconstructions of past climate. J. Climate, 18, 4097-4107, https://doi.org/10.1175/ JCLI3564.1.

_- M. A. Cane, S. E. Zebiak, and A. Clement, 2005b: Volcanic and solar forcing of the tropical Pacific over the past 1000 years. J. Climate, 18, 447-456, https://doi.org/10.1175/ JCLI-3276.1.

_ S. Rutherford, E. Wahl, and C. Ammann, 2007: Robustness of proxy-based climate field reconstruction methods. J. Geophys. Res., 112, D12109, https://doi.org/10.1029/2006jd008272.

—, Z. Zhang, M. K. Hughes, R. S. Bradley, S. K. Miller, S. Rutherford, and F. Ni, 2008: Proxy-based reconstructions of hemispheric and global surface temperature variations over the past two millennia. Proc. Natl. Acad. Sci. USA, 105, 13 252-13 257, https://doi.org/10.1073/pnas.0805721105.

_ , and Coauthors, 2009: Global signatures and dynamical origins of the Little Ice Age and Medieval Climate Anomaly. Science, 326, 1256-1260, https://doi.org/10.1126/science.1177303.

McGregor, H. V., and Coauthors, 2015: Robust global ocean cooling trend for the pre-industrial Common Era. Nat. Geosci., 8, 671, https://doi.org/10.1038/ngeo2510.

McGregor, S., and A. Timmermann, 2011: The effect of explosive tropical volcanism on ENSO. J. Climate, 24, 2178-2191, https://doi.org/10.1175/2010JCLI3990.1.

,$- \ldots$, and O. Timm, 2010: A unified proxy for ENSO and PDO variability since 1650 . Climate Past, 6, 1-17, https:// doi.org/10.5194/cp-6-1-2010.

McIntyre, S., and R. McKitrick, 2005: Hockey sticks, principal components, and spurious significance. Geophys. Res. Lett., 32, L03710, https://doi.org/10.1029/2004g1021750.

Otto-Bliesner, B. L., and Coauthors, 2016: Climate variability and change since $850 \mathrm{CE}$ : An ensemble approach with the Community Earth System Model. Bull. Amer. Meteor. Soc., 97, 735-754, https://doi.org/10.1175/BAMS-D-14-00233.1.

PAGES Hydro2K Consortium, 2017: Comparing proxy and model estimates of hydroclimate variability and change over the Common Era. Climate Past, 13, 1851-1900, https://doi.org/ 10.5194/cp-13-1851-2017.

Pyrina, M., S. Wagner, and E. Zorita, 2017: Pseudo-proxy evaluation of Climate Field Reconstruction methods of North Atlantic climate based on an annually resolved marine proxy network. Climate Past, 13, 1339-1354, https://doi.org/10.5194/ cp-13-1339-2017.

Rutherford, S. D., M. E. Mann, T. Delworth, and R. Stouffer, 2003: Climate field reconstruction under stationary and nonstationary forcing. J. Climate, 16, 462-479, https://doi.org/ 10.1175/1520-0442(2003)016<0462:CFRUSA > 2.0.CO;2.
,-- T. Osborn, K. Briffa, P. D. Jones, R. Bradley, and M. Hughes, 2005: Proxy-based Northern Hemisphere surface temperature reconstructions: Sensitivity to method, predictor network, target season, and target domain. J. Climate, 18, 2308-2329, https://doi.org/10.1175/JCLI3351.1.

, - C. M. Ammann, and E. R. Wahl, 2010: Comments on "A surrogate ensemble study of climate reconstruction methods: Stochasticity and robustness." J. Climate, 23, 28322838, https://doi.org/10.1175/2009JCLI3146.1.

Schneider, T., 2001: Analysis of incomplete climate data: Estimation of mean values and covariance matrices and imputation of missing values. J. Climate, 14, 853-871, https://doi.org/10.1175/ 1520-0442(2001)014<0853:AOICDE > 2.0.CO;2.

Smerdon, J. E., 2012: Climate models as a test bed for climate reconstruction methods: Pseudoproxy experiments. Wiley Interdiscip. Rev.: Climate Change, 3, 63-77, https://doi.org/ 10.1002/wcc.149.

, and A. Kaplan, 2007: Comments on "Testing the fidelity of methods used in proxy-based reconstructions of past climate": The role of the standardization interval. J. Climate, 20, 56665670, https://doi.org/10.1175/2007JCLI1794.1.

— temperature over the past 2000 years: The science behind the headlines. Wiley Interdiscip. Rev.: Climate Change, 7, 746-771, https://doi.org/10.1002/wcc.418.

— , A. Kaplan, and D. E. Amrhein, 2010a: Erroneous model field representations in multiple pseudoproxy studies: Corrections and implications. J. Climate, 23, 5548-5554, https://doi.org/ 10.1175/2010JCLI3742.1.

- - - D. Chang, and M. N. Evans, 2010b: A pseudoproxy evaluation of the CCA and RegEM methods for reconstructing climate fields of the last millennium. J. Climate, 23, 4856-4880, https://doi.org/10.1175/2010JCLI3328.1.

,-- E. Zorita, J. F. González-Rouco, and M. Evans, 2011: Spatial performance of four climate field reconstruction methods targeting the Common Era. Geophys. Res. Lett., 38, L11705, https://doi.org/10.1029/2011gl047372.

, S. Coats, and T. R. Ault, 2016: Model-dependent spatial skill in pseudoproxy experiments testing climate field reconstruction methods for the Common Era. Climate Dyn., 46, 1921-1942, https://doi.org/10.1007/s00382-015-2684-0.

Swingedouw, D., L. Terray, C. Cassou, A. Voldoire, D. SalasMélia, and J. Servonnat, 2011: Natural forcing of climate during the last millennium: Fingerprint of solar variability. Climate Dyn., 36, 1349-1364, https://doi.org/10.1007/s00382010-0803-5.

Tierney, J. E., and Coauthors, 2015: Tropical sea surface temperatures for the past four centuries reconstructed from coral archives. Paleoceanography, 30, 226-252, https://doi.org/ 10.1002/2014PA002717.

Timmermann, A., and Coauthors, 2018: El Niño-Southern Oscillation complexity. Nature, 559, 535, https://doi.org/10.1038/ s41586-018-0252-6.

Ting, M., Y. Kushnir, R. Seager, and C. Li, 2009: Forced and internal twentieth-century SST trends in the North Atlantic. J. Climate, 22, 1469-1481, https://doi.org/10.1175/2008JCLI2561.1.

Tingley, M. P., P. F. Craigmile, M. Haran, B. Li, E. Mannshardt, and B. Rajaratnam, 2012: Piecing together the past: Statistical insights into paleoclimatic reconstructions. Quat. Sci. Rev., 35, 1-22, https://doi.org/10.1016/j.quascirev.2012.01.012.

Trenberth, K. E., and D. J. Shea, 2006: Atlantic hurricanes and natural variability in 2005. Geophys. Res. Lett., 33, L12704, https://doi.org/10.1029/2006g1026894. 
Vecchi, G. A., and A. T. Wittenberg, 2010: El Niño and our future climate: Where do we stand? Wiley Interdiscip. Rev.: Climate Change, 1, 260-270, https://doi.org/10.1002/wcc.33.

von Storch, H., E. Zorita, J. M. Jones, Y. Dimitriev, F. GonzálezRouco, and S. F. Tett, 2004: Reconstructing past climate from noisy data. Science, 306, 679-682, https://doi.org/10.1126/ science.1096109.

Wahl, E. R., D. M. Ritson, and C. M. Ammann, 2006: Comment on "Reconstructing past climate from noisy data." Science, 312, 529, https://doi.org/10.1126/science.1120866.

Wang, J., J. Emile-Geay, D. Guillot, J. Smerdon, and B. Rajaratnam, 2014: Evaluating climate field reconstruction techniques using improved emulations of real-world conditions. Climate Past, 10, 1-19, https://doi.org/10.5194/cp-10-1-2014.

,,,--- N. P. McKay, and B. Rajaratnam, 2015: Fragility of reconstructed temperature patterns over the Common Era: Implications for model evaluation. Geophys. Res. Lett., 42, 7162-7170, https://doi.org/10.1002/2015GL065265.
Wilson, R., A. Tudhope, P. Brohan, K. Briffa, T. Osborn, and S. Tett, 2006: Two-hundred-fifty years of reconstructed and modeled tropical temperatures. J. Geophys. Res. Oceans, 111 C10007, https://doi.org/10.1029/2005jc003188.

—, E. Cook, R. D'Arrigo, N. Riedwyl, M. N. Evans, A. Tudhope, and R. Allan, 2010: Reconstructing ENSO: The influence of method, proxy data, climate forcing and teleconnections. J. Quaternary Sci., 25, 62-78, https://doi.org/10.1002/jqs.1297.

Yeh, S. W., and Coauthors, 2018: ENSO atmospheric teleconnections and their response to greenhouse gas forcing. Rev. Geophys., 56, 185-206, https://doi.org/10.1002/2017RG000568.

Yun, K. S., and A. Timmermann, 2018: Decadal monsoon-ENSO relationships reexamined. Geophys. Res. Lett., 45, 2014-2021, https://doi.org/10.1002/2017GL076912.

Zorita, E., F. Gonzalez-Rouco, and H. Von Storch, 2007: Comments on "testing the fidelity of methods used in proxy-based reconstructions of past climate." J. Climate, 20, 3693-3698, https://doi.org/10.1175/JCLI4171.1. 